\title{
Marine dipole-dipole controlled source electromagnetic and coincident-loop transient electromagnetic experiments to detect seafloor massive sulphides: effects of three-dimensional bathymetry
}

\author{
Amir Haroon, ${ }^{1,2}$ Sebastian Hölz, ${ }^{1}$ Romina A. S. Gehrmann ${ }^{\oplus}, 2$ Eric Attias ${ }^{\oplus,}, 2$ \\ Marion Jegen, ${ }^{1}$ Timothy A. Minshull ${ }^{2}$ and Bramley J. Murton ${ }^{4}$ \\ ${ }^{1}$ Helmholtz Centre for Ocean Research Kiel, GEOMAR, Wischhofstr. 1-3, 24148 Kiel, Germany.E-mail: aharoon@geomar.de \\ ${ }^{2}$ National Oceanography Centre Southampton, University of Southampton, Waterfront Campus, European Way, Southampton, SO14 3ZH, United Kingdom \\ ${ }^{3}$ Hawai 'i Institute of Geophysics and Planetology, School of Ocean and Earth Science and Technology, University of Hawai 'i at Mãnoa, Honolulu, HI 96822, \\ USA \\ ${ }^{4}$ National Oceanography Centre, European Way, Southampton, SO14 3ZH, United Kingdom
}

\section{SUMMAR Y}

Seafloor massive sulphides (SMSs) are regarded as a potential future resource to satisfy the growing global demand of metals including copper, zinc and gold. Aside from mining and retrieving profitable amounts of massive sulphides from the seafloor, the present challenge is to detect and delineate significant SMS accumulations, which are generally located near mid-ocean ridges and along submarine volcanic arc and backarc spreading centres. Currently, several geophysical technologies are being developed to detect and quantify SMS occurrences that often exhibit measurable contrasts in their physical parameters compared to the surrounding host rock. Here, we use a short, fixed-offset controlled source electromagnetic (CSEM) system and a coincident-loop transient electromagnetic (TEM) system, which in theory allow the detection of SMS in the shallow seafloor due to a significant electrical conductivity contrast to their surroundings.

In 2016, CSEM and TEM experiments were carried out at several locations near the TransAtlantic Geotraverse hydrothermal field to investigate shallow occurrences of massive sulphides below the seafloor. Measurements were conducted in an area that contains distinct SMS sites located several kilometres off-axis from the Mid-Atlantic ridge, some of which are still connected to hydrothermal activity and others where hydrothermal activity has ceased. Based on the quality of the acquired data, both experiments were operationally successful. However, the data analysis indicates bias caused by three-dimensional (3D) effects of the rough bathymetry in the study area and, thus, data interpretation remains challenging. Therefore, we study the influence of 3D bathymetry for marine CSEM and TEM experiments, focusing on shallow 3D conductors located beneath mound-like structures. We analyse synthetic inversion models for attributes associated with 3D distortions of CSEM and TEM data that are not sufficiently accounted for in conventional 1D (TEM) and 2D (CSEM) interpretation schemes. Before an adequate quantification of SMS in the region is feasible, these $3 \mathrm{D}$ effects need to be studied to avoid over/underestimation of SMS using the acquired EM data. The sensitivity of CSEM and TEM to bathymetry is investigated by means of 3D forward modelling, followed by $1 \mathrm{D}$ (TEM) and 2D (CSEM) inversion of the synthetic data using realistic error conditions. Subsequently, inversion models of the synthetic 3D data are analysed and compared to models derived from the measured data to illustrate that $3 \mathrm{D}$ distortions are evident in the recorded data sets.

Key words: Marine electromagnetics; Hydorthermal systems; Controlled source electromagnetics. 


\section{INTRODUCTION}

Seafloor massive sulphides (SMSs) refer to an accumulation of minerals on or within the seafloor that may contain high grades of zinc $(\mathrm{Zn})$, copper $(\mathrm{Cu})$, tin $(\mathrm{Sn})$, gold $(\mathrm{Au})$ or silver $(\mathrm{Ag})$ (Doyle $\&$ Allen 2003). SMS are commonly hosted by submarine volcanic successions and appear either in the form of a mound, or through precipitation of hydrothermal fluids exhaled at the seafloor. They are associated with hydrothermal convection (Galley et al. 2007), where cold seawater penetrates deep into the seafloor and is heated to temperatures exceeding $400{ }^{\circ} \mathrm{C}$. The hot fluids leach out minerals from the surrounding rock, making them slightly acidic, reduced and enriched in dissolved metals. They rapidly rise and expel into the water column at vent sites, where accumulations of SMS are commonly formed.

SMS deposits are of growing economic interest as they contain $\mathrm{Cu}, \mathrm{Sn}, \mathrm{Zn}$ and potentially traces of Ag and Au (Galley et al. 2007). Within the active zones of global mid-ocean ridges, and along submarine volcanic arc and backarc spreading centres, the total amount of $\mathrm{Cu}$ and $\mathrm{Zn}$ in accessible SMS deposits is estimated on the order of $3 \times 10^{10} \mathrm{~kg}$ (Hannington et al. 2011). However, a clear quantification is poorly constrained, as off-axes occurrences, which are no longer connected to hydrothermal activity and potentially covered by sediments, are not detectable using the presently available technologies and may significantly increase this estimate (Andersen et al. 2017). To find and delineate possibly unknown SMS occurrences, new geophysical technologies are currently being developed to detect and quantify inactive, off-axes SMS sites to improve the global estimates of mineral deposits on the seafloor. Here, we focus on two systems: first, a towed, fixed-offset three-axis electric field controlled source electromagnetic (CSEM) system (Fig. 1a) and secondly a coincident-loop transient electromagnetic (TEM) system (Figs 1b and c) that were used successfully on a research cruise in the summer of 2016.

In comparison to the surrounding host rock, SMS typically exhibit substantial contrasts in their physical parameters, i.e. magnetic susceptibility (Spagnoli et al. 2017a), acoustic velocity (Spagnoli et al. 2017b) and electrical conductivity (Morgan 2012; Spagnoli et al. 2016). Thus, making them ideal targets for geophysical exploration. Sulphide mounds, particularly at shallow depths beneath the seafloor, have a high porosity and contain metalliferous minerals and clays, which make them more conductive compared to the surrounding host units. Spagnoli et al. (2016) state that the electrical conductivities of SMS are higher compared to the surrounding basalt rock. The basaltic host rock will generally have conductivity values in the order of $0.2 \mathrm{~S} \mathrm{~m}^{-1}$ or lower, whereas SMS deposits in the same region exhibit conductivity values of up to $100 \mathrm{~S} \mathrm{~m}^{-1}$, but generally lie between 1 and $10 \mathrm{~S} \mathrm{~m}^{-1}$.

Based on this significant conductivity contrast, electromagnetic induction methods are ideal geophysical tools to detect and delineate these mineralized zones. The idea of applying TEM systems to map the seafloor for SMS was theoretically introduced by Cheesman et al. (1987). Practical time domain EM experiments were later conducted off the coast of British Colombia (Everett et al. 1988) and at the TAG (Trans-Atlantic Geotraverse) mound (Cairns et al. 1996). At the latter site, a direct current (DC) survey was also published by von Herzen et al. (1996). Since then, the quantity of marine EM experiments targeting on SMS exploration has significantly reduced, as the present focus lies on detecting resistive targets embedded in conductive background sediments associated with hydrocarbon reservoirs (e.g. Constable 2010), gas hydrates (e.g. Schwalenberg et al. 2010), or groundwater (e.g. Haroon et al. 2018). However, the SMS topic was rediscovered by Kowalczyk (2008), who was the first to apply a vertical loop transmitter combined with a horizontal electric field receiver attached on an remotely operated vehicle (ROV) to map the upper meters of the seafloor for SMS accumulations. More recently, Swidinsky et al. (2012) demonstrated that a horizontal loop source is applicable to delineate conductive layers in the shallow seafloor associated with SMS. In fact, horizontal loop sources are particularly effective because they show nearly no sensitivity to seafloor structures with conductivities lower than the seawater (Swidinsky et al. 2012). Consequently, only accumulations of SMS with a bulk conductivity greater than $\sim 1 \mathrm{~S} \mathrm{~m}^{-1}$ cause a significant response in the induced voltage of a loop receiver.

Recently, several loop transmitter/receiver systems have been developed and successfully applied that measure either in the time domain (Hölz et al. 2015), frequency domain (Müller et al. 2015; Müller et al. 2016), or use an ROV to navigate close to the seafloor (Kowalczyk 2008, 2011, 2013; Asakawa et al. 2016; Nakayama \& Saito 2016). Our study focuses on the MARTEMIS system developed by Hölz et al. (2015), which is towed in the immediate proximity of the seafloor behind the vessel (Figs $1 \mathrm{~b}$ and c). A pilot MARTEMIS survey conducted at the Palinuro Seamount in the Tyrrhenian Sea detected higher seafloor conductivities near previously drilled SMS accumulations (Hölz et al. 2015), thereby confirming the effective applicability of the MARTEMIS system for SMS exploration.

A further marine EM experiment that is effective in detecting shallow conductive structures is the fixed-offset electric dipoledipole system using a deep-towed active source instrument (DASI; Sinha et al. 1990) and a three-axis electric field receiver named Vulcan (Constable et al. 2016). In the following, we will refer to this system as the DASI-Vulcan system to avoid confusion to the standard CSEM application that uses stationary, seafloor-based EM receivers. The applied dipole-dipole system is sensitive to resistive targets (e.g. Weitemeyer \& Constable 2010), but may also be used to detect conductive targets. In general, the DASI-Vulcan system has a larger penetration depth and wider footprint compared to the smallscale MARTEMIS system. The Vulcan receivers are towed behind the source, measuring the three-component electric field response of the surrounding environment (Fig. 1a). They were developed to accompany standard CSEM applications that utilize Ocean Bottom EM (OBEM) receivers to increase the resolution of CSEM in the shallow regions of the seafloor (e.g. Attias et al. 2018). During the experiment in summer 2016, the Vulcan-based CSEM system was utilized for SMS exploration for the first time.

As aggregations of SMS are often associated with mound-like structures, rough seafloor topography may cause measurable 3D distortions in the acquired EM data. These distortions are often insufficiently accounted for or even neglected due to (relatively) flat bathymetry in marine EM experiments (Li \& Constable 2007). This concern has been addressed in 2.5D modelling studies ( $\mathrm{Li} \&$ Constable 2007) and, more recently, in 3D modelling studies that investigate the effect of 3D bathymetry on CSEM data (Schwarzbach et al. 2011). However, both above-mentioned publications confine their focus to relatively deep resistive targets embedded in conductive background environments and, additionally, only consider stationary, seafloor-based receivers along with a towed horizontal electric dipole transmitter. Here, we analyse data from a towed, fixed-offset CSEM system that measures the horizontal $\left(E_{x}, E_{y}\right)$ and vertical $\left(E_{z}\right)$ electric field components at relatively short distances to the source. Thus, increasing the susceptibility towards distortions caused by the 3D bathymetry. Moreover, since the conductive SMS target is an integral part of the topographic expression 
(a)

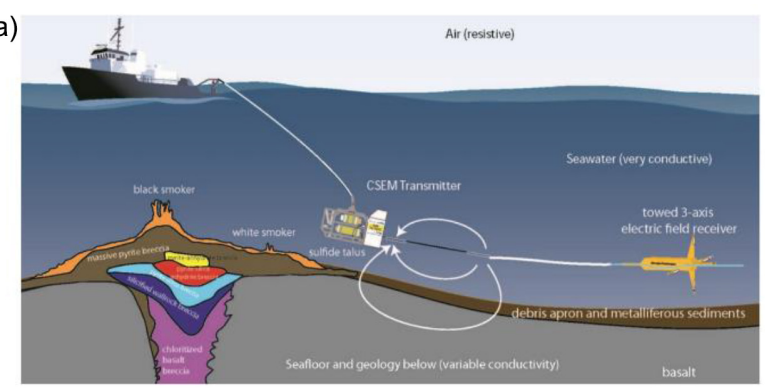

(b)

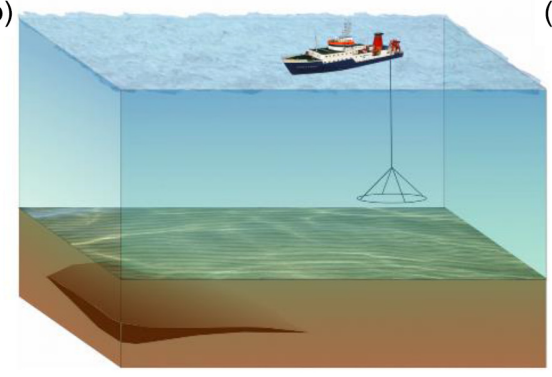

(c)

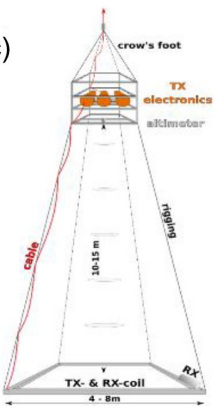

Figure 1. Schematics of the applied EM systems. (a) The DASI-Vulcan system of the University of Southampton consisting of a $50 \mathrm{~m}$ horizontal electric dipole source and two, three-component Vulcan EM receivers towed in-line behind the transmitter [image is modified from Rona (2008) and references within; Hannington et al. (1995) and Weitemeyer et al. (2006)]. (b) Marine horizontal loop application (courtesy of Malte Sommer) and (c) MARTEMIS system designed and built at GEOMAR. A $6.3 \times 6.3 \mathrm{~m}^{2}$ square transmitter loop was utilized as the exciting source. The induced voltage is measured by a coincident horizontal receiver coil.

along the seafloor, the expected 3D distortions in these data cannot be quantified accurately based on the previously published studies alone. A reliability analysis of the standard interpretation schemes for MARTEMIS using a self-developed 1D inversion, as well as the DASI-Vulcan system using the MARE2DEM inversion (Key 2016), is inevitable for these types of 3D environments to minimize data uncertainty and avoid inaccurate quantification of SMS in the region.

We apply three-dimensional (3D) forward modelling to analyse the effects of a mound-shaped structure on DASI-Vulcan and MARTEMIS data. The synthetic 3D data are interpreted using the standard inversion procedure for each EM method under realistic error conditions. The inversion models are subsequently evaluated for artefacts attributed to the 3D bathymetry and compared to a representative subset of the measured data. Comparable conductivity anomalies in the inversion models of the synthetic and measured DASI-Vulcan and MARTEMIS data are used to determine if the acquired data may, at least in part, be distorted by the 3D bathymetry. Subsequently, we qualitatively identify if these inherited conductivity anomalies will lead to over/underestimation of existing SMS in the area, and limit the quantification of exploitable massive sulphides within the marine environment.

\section{EXPERIMENTAL SET-UP}

The survey area contains prominent bathymetry anomalies associated with SMS sites named Shinkai, Southern and Double mounds and, additionally, comprises steep cliffs and valleys (Fig. 2). Due to its cone-shaped dimensions, Shinkai is of particular interest for the 3D forward modelling studies, as it rises nearly $90 \mathrm{~m}$ above the surrounding seafloor, with a base diameter of only around $200 \mathrm{~m}$ and a slope of nearly $45 \mathrm{deg}$ (see Fig. 2). A considerable 3D distortion is therefore expected in the recorded EM data sets.

Geophysical experiments that were carried out in the work area included CSEM and TEM measurements conducted with the DASIVulcan and MARTEMIS system at challenging water depths greater than $3.5 \mathrm{~km}$. The two EM surveys have different objectives in terms of resolution and, therefore, are considered complimentary to each other. The DASI-Vulcan system is used to acquire EM data on a regional scale aiming to detect large-scale conductivity anomalies up to several hundred metres beneath the seafloor. In turn, the coincident-loop MARTEMIS system is applied to detect small- and large-scale conductivity anomalies in specific regions to resolve the lateral dimensions of SMS accumulations in the shallow seafloor up to depths of $\sim 50 \mathrm{~m}$.

An excerpt of the CSEM and TEM survey is displayed in Fig. 2 by white, purple and red markers. MARTEMIS data were acquired along eight NW-SE profiles that cross directly over visually confirmed SMS deposits on Shinkai and Southern mounds. Stations highlighted in red lie directly above Shinkai and will be evaluated using 1D inversion in Section 5 of this study. DASI-Vulcan data were acquired along six profiles on a regional scale (Gehrmann et al. 2017). One NW-SE profile (displayed by white markers in Fig. 2) crosses Shinkai and Southern Mound with collocated MARTEMIS data and is used in the 2D inversion analysis of Section 5.

\subsection{DASI-Vulcan system}

The towed DASI-Vulcan system consisted of a $50 \mathrm{~m}$ horizontal electric dipole transmitter and two Vulcan receivers located at offsets of $350 \mathrm{~m}$ and $505 \mathrm{~m}$. Due to the rapidly fluctuating seafloor topography, navigation of the towed system was difficult to control and as a consequence, the transmitter and receivers were often located several tens of metres from the intended track and frequently not at the same elevation above the seafloor (Figs 2a and b). In areas of flat bathymetry, these navigational alterations may cause an insignificant uncertainty in the acquired data, especially in the in-line electric field component $\left(\mathrm{E}_{\mathrm{y}}\right)$ that can be compensated in the inversion procedure by increasing the relative error floor (Constable et al. 2016). However, in our study, the rough background bathymetry raises two issues that need to be addressed prior to interpreting the recorded data:

(1) A 2D inversion approach using MARE2DEM (Key 2016) assumes that the resistivity structure perpendicular to the profile remains constant (see Fig. S1 in the Supporting Information). Clearly, this is not the case for the cone-like geometry of Shinkai. Hence, an analysis needs to be conducted to identify how the changes in off-profile bathymetry influence the 2D inversion models.

(2) Although high-resolution 3D bathymetry data exist, they do not allow us to project the profile accurately onto a $2 \mathrm{D}$ model required for the inversion procedure. Since transmitter and receivers are not located on the same intended track, it remains unclear which projected 2D bathymetry is applicable for inversion. Hence, transmitter and/or receiver altitudes will be incorrect in the 2D inversion approach, depending on the choice of $2 \mathrm{D}$ projection. It is important to know whether the projected $2 \mathrm{D}$ bathymetry provides a sufficiently 
(a)

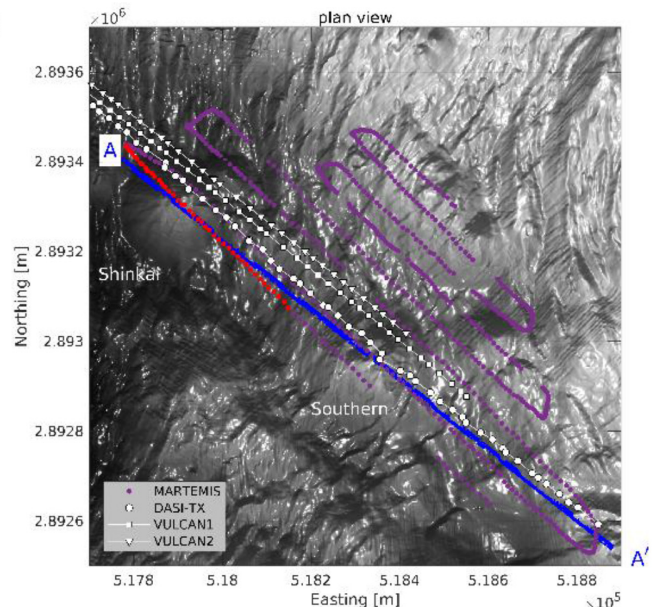

(b)

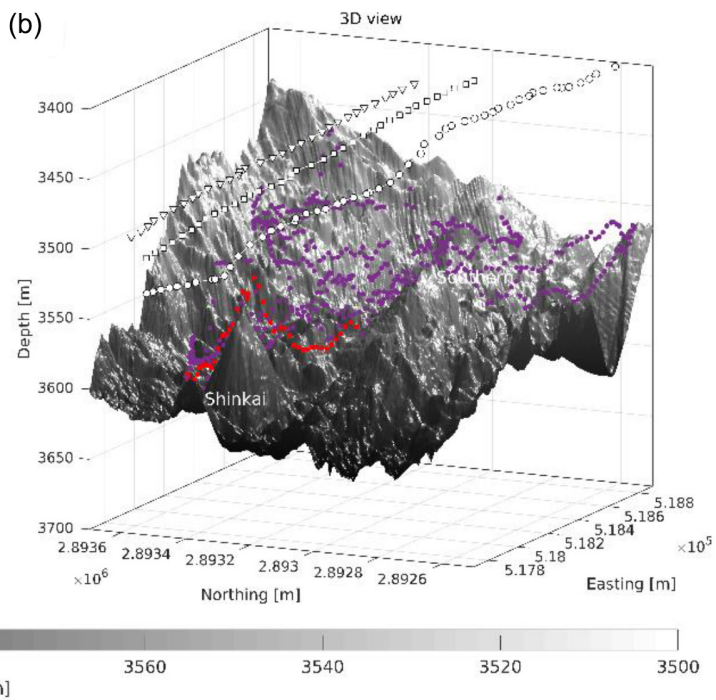

Depth $[\mathrm{m}]$

(c)
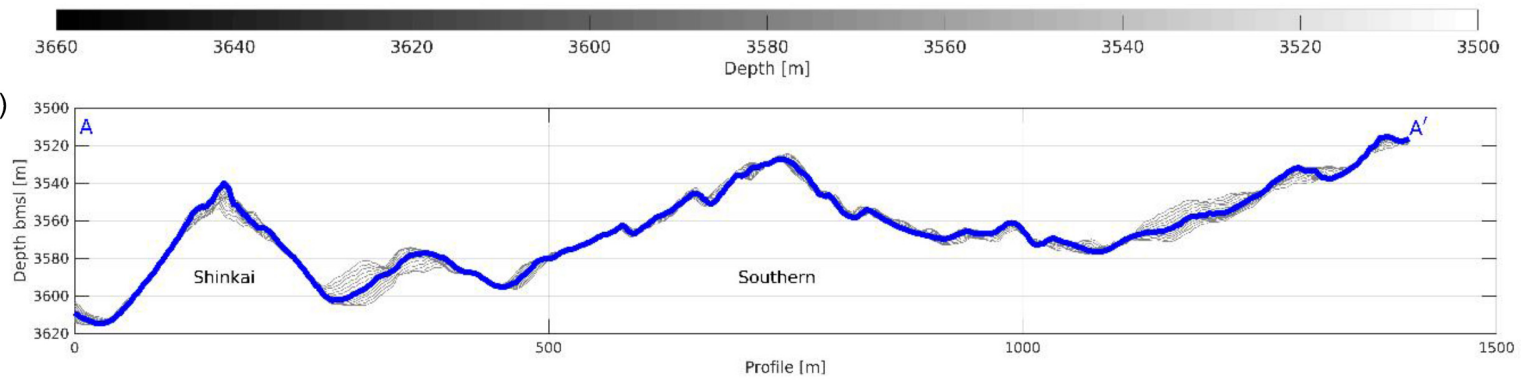

Figure 2. (a) High-resolution bathymetry acquired by the autonomous underwater vehicle (AUV) ABYSS (GEOMAR) gridded at a resolution of $2 \mathrm{~m}$ overlain by the locations of the MARTEMIS data (purple), the DASI transmitter dipole (white circles) and VULCAN receivers (squares and triangles for first and second receiver, respectively). The red markers highlight the MARTEMIS stations that are investigated and compared to synthetic models in the extent of this study. (b) 3D representation of the bathymetry model shown in (a) to exemplify the expected 3D effect of the bathymetry. Note that the vertical exaggeration of the bathymetry in (b) is 4:1. Bathymetry data are courtesy of S. Petersen and the AUV ABYSS team (GEOMAR). (c) Bathymetry along profile A-A' for better representation. Grey lines represent parallel off-axes profiles of $\pm 10 \mathrm{~m}$.

accurate estimate to fit the data without introducing additional artefacts in the inversion model.

In Sections 4 and 5, we use a projected 2D bathymetry model to interpret the synthetic and measured CSEM data using 2D inversion. We identify how the above-mentioned issues influence the 2D interpretation of $3 \mathrm{D}$ data. Additionally, a comparison between 2D and 3D data calculated for the synthetic models of this study are displayed in the Supporting Information Fig. S2.

\subsection{Coincident-loop MARTEMIS system}

The MARTEMIS system consisted of a coincident $6.3 \times 6.3 \mathrm{~m}^{2}$ square loop. Although the system is more compact than DASIVulcan, we investigate the influence of a 3D mound on 1D inversion models, which are used as the primary interpretation tool for the acquired data. One-dimensional inversion is often considered a sufficient interpretation tool for loop applications since the method is most sensitive to the structure directly beneath, or close to the location of the antenna (Swidinsky et al. 2012). Consequently, it is frequently convenient to approximate the seafloor conductivity structure using models that consist of stacked horizontal layers with certain thickness and conductivity. However, steep slopes of $45^{\circ}$ are rarely surveyed using TEM methods, both on land and at sea. Moreover, comparable coincident-loop data are currently not available to verify that a $1 \mathrm{D}$ inversion is applicable to adequately resolve the subsurface conductivity structure in regions of rough bathymetry. The presented analysis will test the reliability of using $1 \mathrm{D}$ inversion to interpret the acquired MARTEMIS data and identify any inherited inversion artefacts that may appear in the resulting models.

\section{3 D FORWARD MODELLING}

Forward modelling studies concerning axial symmetric TAG-like structures have been published for dipole sources in the time domain (Yu \& Edwards 1996). Here, similar models in three dimensions are utilized to investigate the seafloor response of the applied measurement systems. For frequency domain CSEM (DASI-Vulcan), 3D forward modelling was conducted using COMSOL Multiphysics (Comsol 2017). A base frequency of $1 \mathrm{~Hz}$ was chosen along with odd harmonics up to $9 \mathrm{~Hz}$, corresponding to the data acquired during the experiment. Only amplitudes of the vertical $\left(E_{\mathrm{z}}\right)$ and inline $\left(E_{y}\right)$ electric field are considered, as the measured phase data are unreliable at the time of this study due to timing uncertainties that do not affect amplitudes.

For the synthetic modelling study, we use the average transmitterreceiver geometries from the measurement. The first Vulcan receiver (in the following referred to as Vulcan 1 and displayed in Fig. 3a by orange markers) is located at an offset of $350 \mathrm{~m}$, positioned $24 \mathrm{~m}$ laterally and $28 \mathrm{~m}$ vertically from the transmitter line. The second Vulcan receiver (Vulcan 2 displayed in Fig. 3a by yellow markers) is at an offset of $505 \mathrm{~m}$, positioned $28 \mathrm{~m}$ laterally and $55 \mathrm{~m}$ vertically from the transmitter line. The transmitter elevation is assumed constant along the profile at $120 \mathrm{~m}$ above the flat seafloor and $30 \mathrm{~m}$ above the mound summit. Of course, this is not comparable to the actual experiment, where the transmitter elevation is constantly 
CSEM

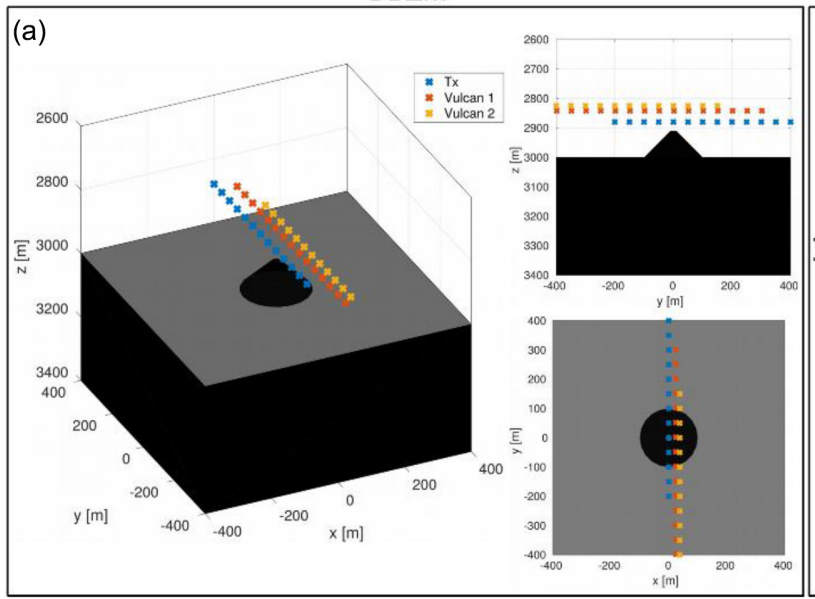

TEM

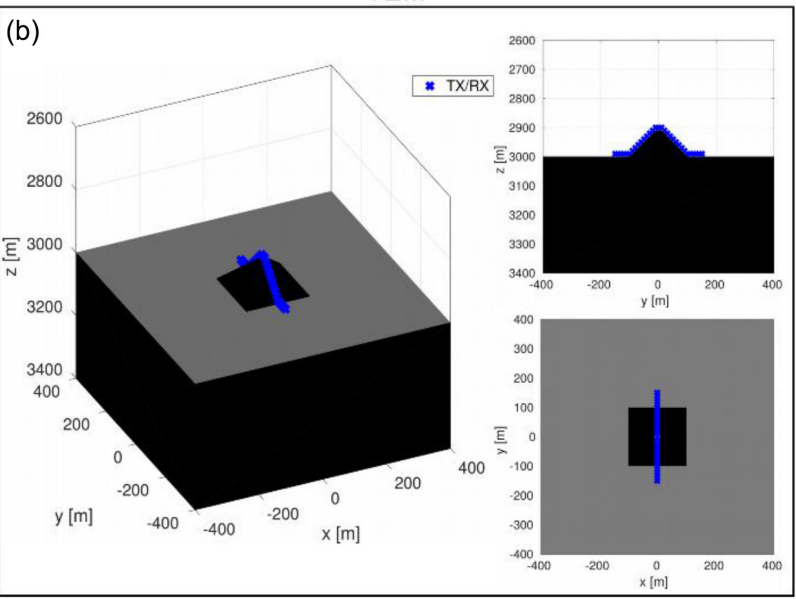

Figure 3. General 3D model and transmitter/receiver geometry applied in the 3D forward modelling study. (a) A truncated cone of $100 \mathrm{~m}$ base radius and height of $90 \mathrm{~m}$ utilized for the CSEM forward modelling. (b) Pyramid with side lengths of $200 \mathrm{~m}$ and height of $90 \mathrm{~m}$ for TEM forward modelling. The coloured markers indicate the position of the transmitter/receivers as indicated by the legend. Each panel shows a 3D representation along with a $2 \mathrm{D}$ cross-section (upper right) and 2D plan view (lower right).

changing along the profile. However, the 3D forward modelling study aims to identify effects of the mound structure and neglects the navigational uncertainty that influences the interpretation of the recorded data.

TEM 3D forward modelling is conducted using the finite difference algorithm sldmem $3 t$ by Druskin \& Knizhnermann (1994). Transients are calculated for a coincident loop configuration at equidistant station locations located $10 \mathrm{~m}$ apart (displayed by blue markers in Fig. 3b). The considered time range is from 0.1 to $50 \mathrm{~ms}$ and a constant elevation of $10 \mathrm{~m}$ above the bathymetry is assumed, corresponding to the mean elevation achieved during the measurements.

One limitation of using different 3D forward modelling software (and thus different model parametrization technique) is the subtle difference between the models for CSEM and TEM forward calculations (Figs 3a and b). The general structure of the 3D model roughly corresponds to the geometry of Shinkai, as illustrated in Fig. 2. The model consists of a truncated cone that sits on a flat homogenous seafloor with a base diameter of $200 \mathrm{~m}$, a peak diameter of $20 \mathrm{~m}$ and a height of $90 \mathrm{~m}$. The slope along the outer surface is $45^{\circ}$. In our 3D CSEM forward models, COMSOL Multiphysics allows a discretization using finite elements. In contrast, discretizing a cone using a finite difference mesh in sldmem $3 t$ is difficult due to the curvature of the inner and outer surfaces. Therefore, we alter the model in the 3D TEM forward modelling to a pyramid with comparable dimensions. The pyramid extends $200 \mathrm{~m}$ at its base with a height of $90 \mathrm{~m}$ at its centre (Fig. 3b). The summit is a $20 \times 20 \mathrm{~m}^{2}$ square area. As the coincident-loop resolution is mainly confined to the areas in the direct vicinity of the coil, the differences between a cone and pyramid shape are considered negligible.

The 3D forward modelling study investigates the field response for five different conductivity models displayed in Fig. 4. The models are illustrated as 2D cross-sections ( $y z$-plane) through the mound centre $(x=0 \mathrm{~m})$. Since SMS deposits around the globe are diverse in terms of structure and composition, and additional high-resolution geophysical or borehole data are currently unavailable for Shinkai, we used conductivity models inspired by the geological SMS model presented by Galley et al. (2007). Here, we alter the base model while keeping mound dimensions constant. The background conductivity of the seafloor and seawater are also constant at 0.2 and
$3 \mathrm{~S} \mathrm{~m}^{-1}$, respectively. Note that compared to the true, complex geometry of an SMS mound, our models are rather simplistic.

Model 1, displayed in Fig. 4(b), assumes a basalt mound with a conductivity of $0.2 \mathrm{~S} \mathrm{~m}^{-1}$. This model represents a mound of volcanic origin or any other bathymetry anomaly without an associated SMS deposit. The model will identify the effect of 3D bathymetry on the acquired TEM/CSEM data. Model 2 represents a homogeneous massive sulphide mound with a conductivity of $10 \mathrm{~S} \mathrm{~m}^{-1}$ (Fig. 4c). This is the counterexample to Model 1 and serves as a reference for the analysis of Model 3 through Model 5. Differences in field amplitude can indicate if the TEM or CSEM applications can detect smaller SMS occurrences and differentiate between heterogeneous/homogeneous mounds.

Model 3 to Model 5 introduce various scenarios of plausible conductivity distributions within the mound (Figs $4 \mathrm{~d}-\mathrm{f}$ ). These three models represent either small-scale SMS accumulations, accumulations of a certain thickness, or buried accumulations. Thereby, Model 3 consists of a small-scale SMS occurrence of $10 \mathrm{~S} \mathrm{~m}^{-1}$ at the mound summit and a less conductive core of $1 \mathrm{~S} \mathrm{~m}^{-1}$. The latter could represent the stockwork and fluid channels of the hydrothermal system with conductivities that classify between the host rock and SMS. The outer shell of the mound has a $30 \mathrm{~m}$ thickness and is assumed to be basaltic host rock with a conductivity of $0.2 \mathrm{~S} \mathrm{~m}^{-1}$. Model 4 differs only in the conductivity of the outer shell, replacing the host rock of Model 3 with SMS. The stockwork remains less conductive with $1 \mathrm{~S} \mathrm{~m}^{-1}$. In comparison, Model 5 has an overburden of $1 \mathrm{~S} \mathrm{~m}^{-1}$ that covers existing SMS in the core. This model represents an SMS deposit where hydrothermal activity has ceased consisting either of sedimentary cover, or an altered overburden due to corrosion of the mineralized materials on the seafloor with buried massive sulphides $\left(10 \mathrm{~S} \mathrm{~m}^{-1}\right)$ beneath.

\subsection{DASI-Vulcan system}

For a CSEM transmitter position close to the mound ( $y=150 \mathrm{~m}$, $z=2880 \mathrm{~m}$ ), the EM field absolute amplitude distributions in the $y z$-plane at $1 \mathrm{~Hz}$ are displayed in Fig. 5 for $E_{y}$ and $E_{z}$. This figure illustrates the physics that controls the CSEM experiment and helps to identify regions of significant amplitude perturbations for a given 

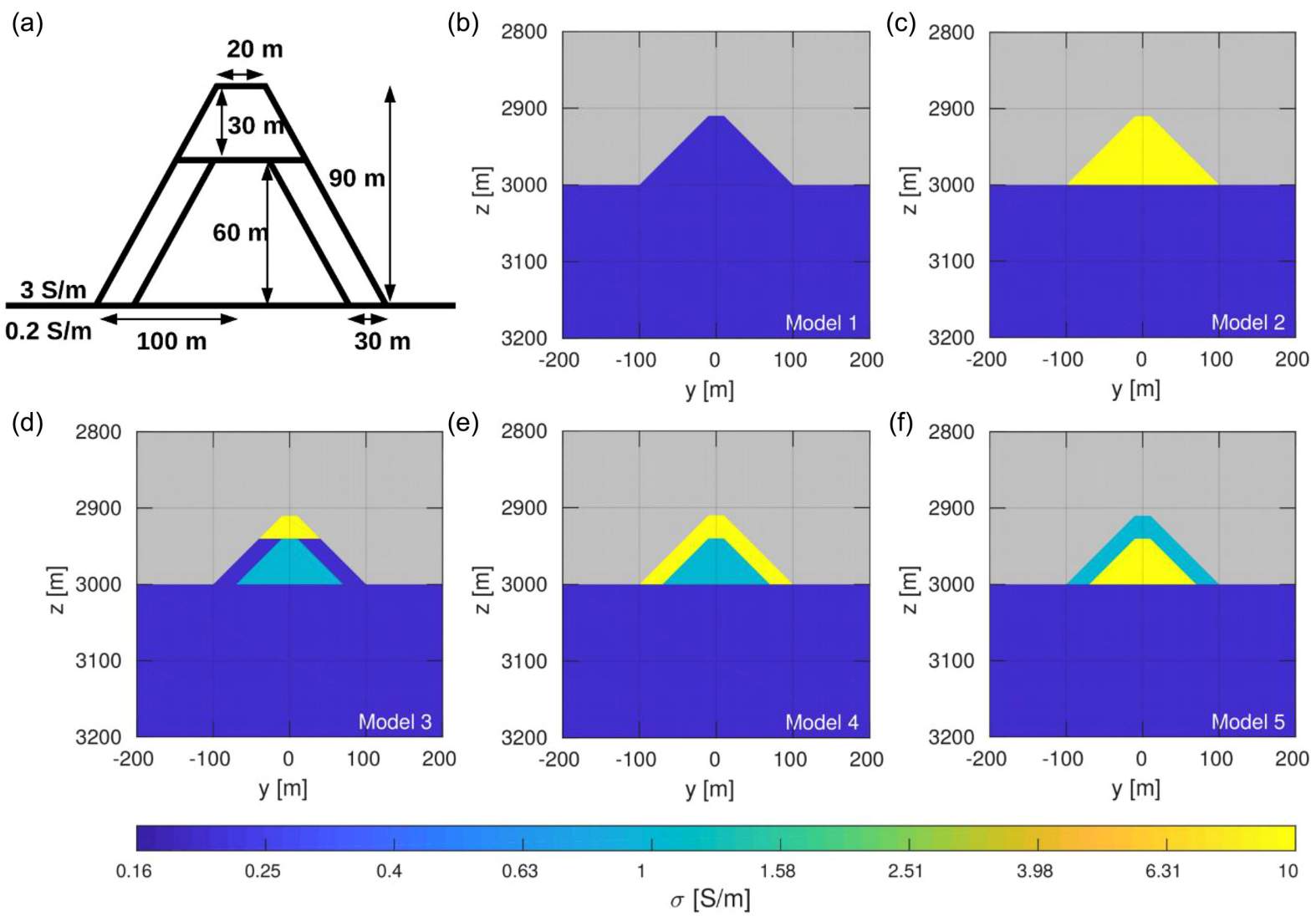

Figure 4. 2D cross-section of the investigated 3D conductivity models. (a) Schematic of the mound dimensions and fixed conductivity values of the host rock and seawater. The five considered conductivity distributions are illustrated in $\mathrm{b}$ through $\mathrm{f}$.
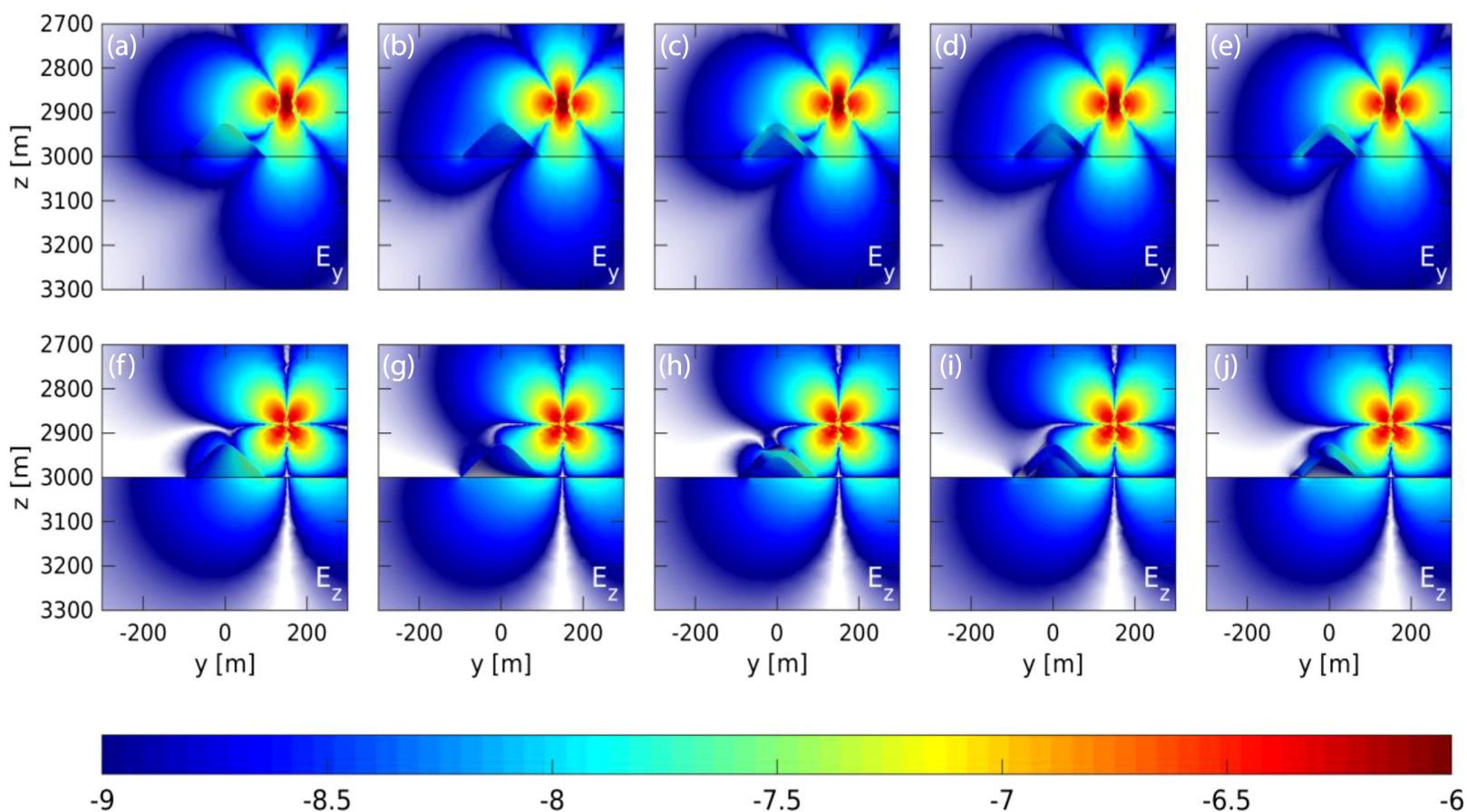

$-8.5$
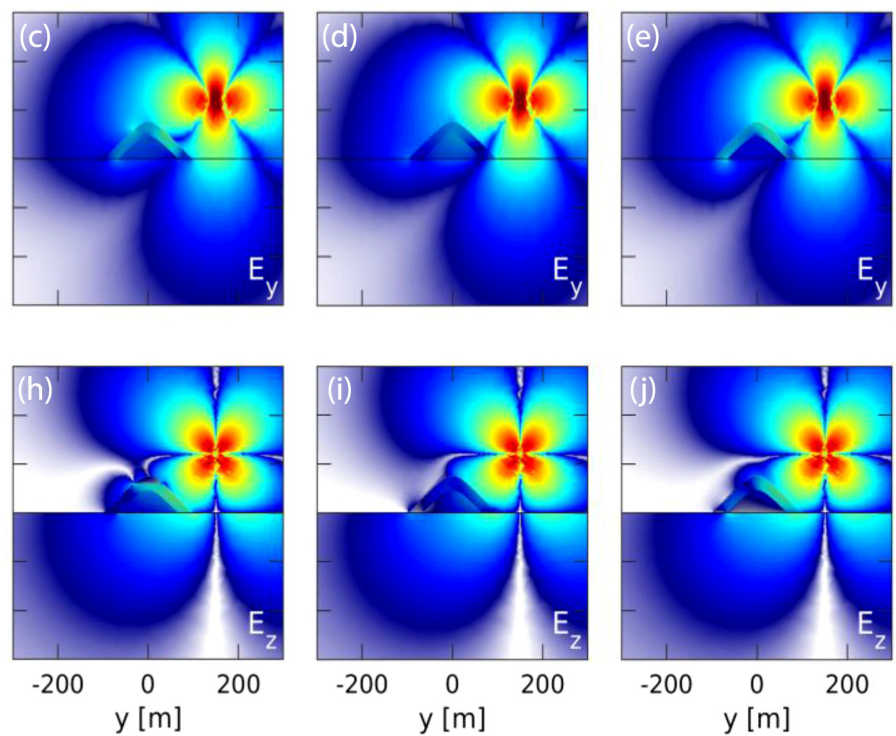

$E_{y}$

$-8$
$-7.5$

$\log _{10}($

(E) $[\mathrm{V} / \mathrm{m}]$

Figure 5. Absolute electric field amplitude of the $E_{y}$ (top panel) and $E_{z}$ (bottom panel) component in the $y z$-plane at $1 \mathrm{~Hz}$ for a horizontal electrical dipole located at $y=150 \mathrm{~m}$. Note, $y z$-plane is shown as a cross-section in the plane of the first Vulcan receiver $(x=24 \mathrm{~m})$. Images are sorted according to their corresponding models (1 through 5) illustrated in Fig. 4 from left to right. Amplitudes below $10^{-9} \mathrm{~V} \mathrm{~m}^{-1}$ are blanked. 
3D conductivity model. This approach is particularly useful for understanding where a maximum response for a given conductivity distribution is measurable. To highlight differences between the models, relative responses are introduced in Fig. 6 and plotted with respect to each other in Fig. 7. Here, the relative response (sometimes also referred to as the detectability) is defined as the relative difference between signal amplitudes for each model displayed in Fig. 5 .

The electric field amplitudes $E_{y}$ and $E_{z}$ show perturbations throughout the model. Amplitude differences are apparent within the seafloor $(z>3000 \mathrm{~m})$, the mound, and within the water column surrounding mound. Amplitude differences are especially prominent in the $E_{z}$ component illustrated in the bottom panels of Fig. 5. In comparison, the $E_{y}$ component (Fig. 5, top panels) shows smaller relative differences, suggesting a lower sensitivity towards changes in the sub-seafloor conductivity structure.

To analyse the field distribution in greater detail, Fig. 6 illustrates the relative response between Model 1 (homogeneous basalt mound; Fig. 4b) and Model 2 (homogeneous SMS mound; Fig. 4c). We choose to focus on these two models first, as they exhibit the largest amplitude differences. Note that the relative response must be significantly larger than the expected relative error (not considered in Fig. 6) to be measurable. The amplitudes differ by approximately 10-20 per cent at the receiver locations, suggesting that a homogenous SMS mound is detectable using the applied survey configuration. Yet, stronger perturbations exceeding 80 per cent appear at lower altitudes above the mound for $E_{z}$ and at the foot of the mound for $E_{y}$. Overall, the highest response is measurable between the seafloor and the source altitude indicating that receivers should ideally be placed below this elevation. Unfortunately, the analysis suggests that the Vulcan receivers were generally not located in regions with the largest target response during the experiment. Thus, future DASI-Vulcan experiments targeting SMS could use additional receivers at shorter offsets and lower measurement altitudes to increase sensitivity.

Relative responses of the remaining models (Fig. 7) show that regions of significant detectability (red and blue regions) are broader and more prominent in the $E_{z}$ component. This behaviour validates the forward modelling studies of Constable et al. (2016) that show similar results for a resistive $2 \mathrm{D}$ structure. However, it needs to be considered that $E_{z}$ field amplitudes are orders of magnitude smaller than $E_{y}$ at these short offsets, and navigational uncertainties cause distortions that are several times larger [see Constable et al. (2016) - Figs 12 and 13 and Fig. S4 in the Supporting Information]. Therefore, $E_{z}$ is less robust in terms of signal to noise and, additionally, more susceptible towards bias caused by field distortions attributed to navigational uncertainty.

The highest detectability is observed in the top row and first column of Fig. 7, suggesting that the presence of conductive SMS will create a measurable perturbation in the electric field amplitude. This underlines the applicability of DASI-Vulcan CSEM for SMS exploration provided that receivers are placed at suitable offsets and elevations to the source. However, the relative response should not be confused with resolution and/or sensitivity to the targets lateral or vertical geometry, as Models 2 and 4 show very little amplitude variation at the receiver altitude $(<10$ per cent). Hence, depending on the measurement geometry, tow altitude and achieved measurement error, such towed experiments may fail to differentiate between a homogeneous and heterogeneous SMS mound. Moreover, smallscale SMS deposits represented by Model 3 are difficult to detect and require a favourable survey geometry and error model. This limitation also applies to Model 5, which exhibits a weak relative response of less than 10 per cent for $E_{y}$ within the water column compared to the other models. Consequently, the detectability of small or buried SMS deposits using only two Vulcan receivers at offsets of 350 and $505 \mathrm{~m}$ seems questionable.

A relative response that exceeds 100 per cent is often found inside the mound. We infer that the best resolution regarding the geometry and possibly conductivity of the SMS deposit can be achieved for receivers located directly on the mound, or within a borehole in the mound. However, based on the strong field perturbations inside the mound, an interpretation of such data would likely require a $3 \mathrm{D}$ inversion.

\subsection{Coincident-loop MARTEMIS system}

Compared to the DASI-Vulcan system, the geometry of MARTEMIS is more controllable, as it consists of a rigid loop hanging at a certain distance beneath the electronics cage (Fig. 1c). Additionally, the real time navigation allows the surveyor to navigate close to the seafloor, thereby increasing seafloor coupling of the excited EM field. Since MARTEMIS measures the vertical magnetic flux density at the centre of the transmitter frame, an analysis as is shown in Figs 5-7 seems redundant. Instead, we only consider the field amplitude calculated at the centre of the loop source.

For loop measurements, it is common practice to transform the measured induced voltages into so-called apparent resistivity $\rho_{\mathrm{a}}$ or apparent conductivity $\sigma_{\mathrm{a}}=1 / \rho_{\mathrm{a}}$, e.g. following Ward \& Hohmann (1988). This transformation gives the interpreter a general overview of the sub-surface conductivity distribution, which can be used to evaluate the basement structure prior to inversion (e.g. Yogeshwar \& Tezkan 2017). A similar transformation is applicable to marine data using a whole-space transformation introduced by Swidinsky \& Weiss (2017). The whole-space transformation for time-dependent induced voltage $V(t)$ to apparent conductivity $\sigma_{a}(t)$ is written as

$\frac{1}{\sigma_{a}(t)}=\rho_{a}(t) \cong\left(\frac{4^{3 / 2} V(t)}{\sqrt{\pi} I a^{4} \mu_{0}^{5 / 2}} t^{5 / 2}\right)^{-2 / 3}$,

where $\rho_{a}(t)$ is the apparent resistivity in $\Omega \mathrm{m}, t$ is time in s, $I$ is current amplitude in A and $a$ is the radius of a circular loop in $\mathrm{m}$. Here, we approximate the radius of the circular loop so that its total area matches the area of the rectangular loop.

For a given transmitter elevation above the boundary of a double half-space model, synthetic apparent conductivity curves are illustrated in Fig. 8. The solid lines represent the seafloor-based coincident loop $(h=0 \mathrm{~m})$, which naturally exhibits the largest seafloor signature at late times. At $t>1 \mathrm{~ms}$, the curves converge towards the mean conductivity of the upper and lower half-space. This implies that the transformed signal disregards a resistive seafloor as its contribution to the late-time $\sigma_{\mathrm{a}}$ curve will be irrelevant. In contrast, a conductive seafloor will dictate the late-time value of $\sigma_{\mathrm{a}}$. If the loop is elevated, the curves diverge at later times of the transient and reach the mean conductivity. In the time range of Fig. 8, the curves do not reach the mean value of the whole-space, but differences between the curves are distinguishable at $t>1 \mathrm{~ms}$. As antenna elevation increases, the curve differences are less pronounced, limiting the dynamic range of the transformed values. This shows that a requirement exists to situate the loop at low elevations above the seafloor in order to achieve a measurable sensitivity to the sub-surface conductivity structure. The required elevation is thereby influenced by the source moment, transient length and signal-to-noise ratio.

For the conductivity models illustrated in Fig. 4, induced voltages are transformed to apparent conductivities to target lateral 

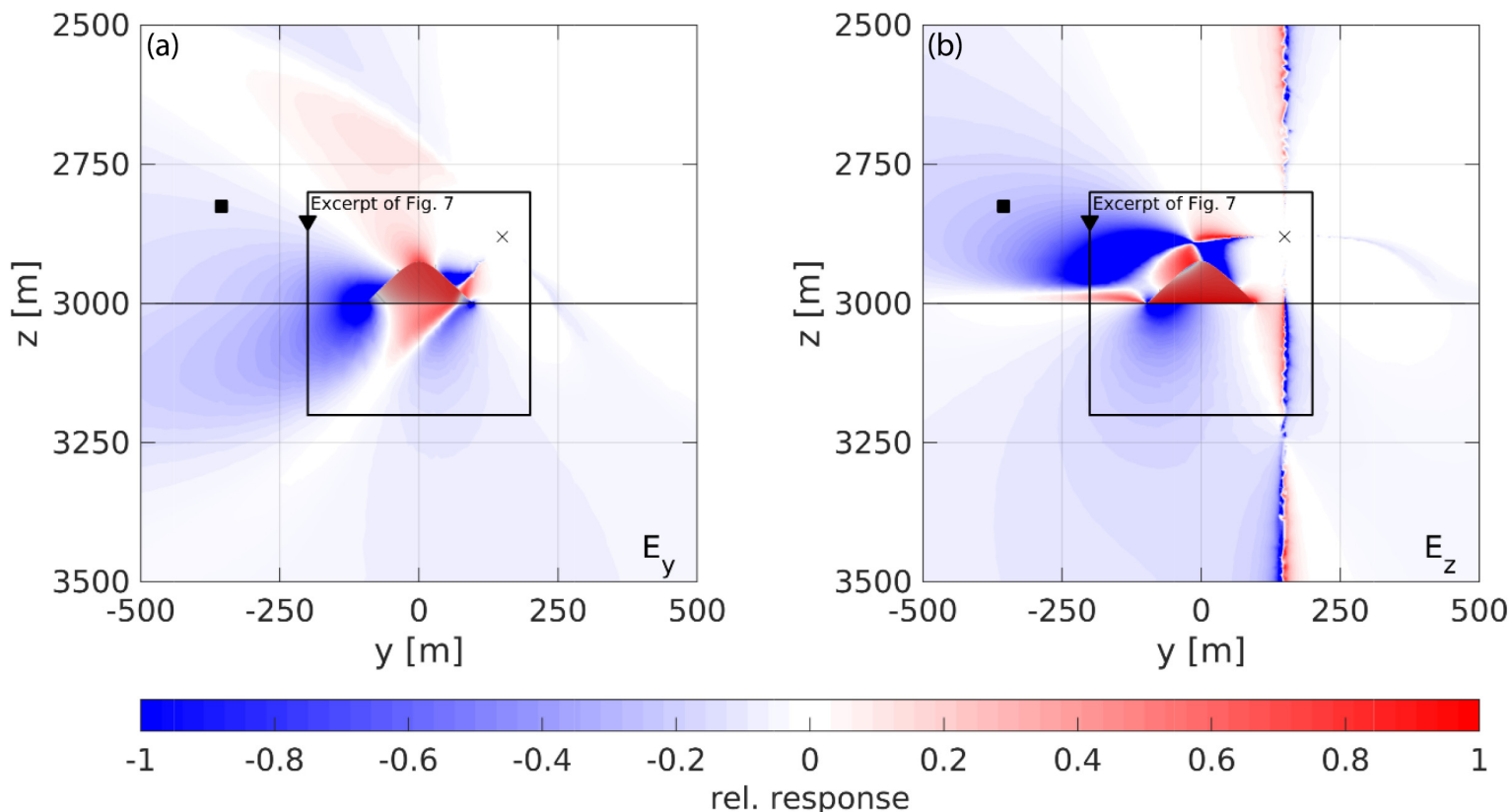

Figure 6. Relative response of Model 1 with respect to Models 2 is calculated for (a) $E_{\mathrm{y}}$ and (b) $E_{\mathrm{z}}$. The location of the transmitter is highlighted by the cross, whereas mean receiver locations during the measurement survey are shown by a triangle and square for the first and second Vulcan, respectively. The relative response is plotted for values between 1 and $^{-} 1$, which corresponds to a relative difference in signal amplitude of \pm 100 per cent. The axis ranges are increased compared to Fig. 5 to display the Vulcan receiver locations.

conductivity changes along the profile. The transformed data may be displayed as pseudo-sections or profile curves for specific time delays $(\mathrm{d} t)$. Fig. 9 shows the pseudo-sections (top panels) and profile curves (bottom panels) for Model 1 (left) through Model 5 (right). The selected time delays of 3.7, 8 and $19.3 \mathrm{~ms}$ lie within the interpretable range of a typical marine transient EM error model (following Hölz et al. 2015) and are highlighted by dotted, dashed and solid lines, respectively. Due to the symmetry of the models, apparent conductivity pseudo-sections and profile curves are symmetric around $y=0 \mathrm{~m}$. The pseudo-sections differ considerably between the models with the exception of Model 2 and Model 4, which are nearly identical and differ only at late times (solid line of Figs $9 \mathrm{~g}$ and i). This observation suggests that for the considered time range, MARTEMIS data will distinguish poorly between a homogeneous SMS mound and one that has a $30 \mathrm{~m}$ thick, conductive shell. However, MARTEMIS is sensitive to small-scale conductive structures within the mound summit (Fig. 9c), and conductive structures that may be buried beneath several metres of sediments or altered material (Fig. 9e).

At selected time delays (Figs 9f-j), the following signal characteristics are apparent. Responses of Model 1 (Fig. 9f) are characterized by a steady increase of apparent conductivity from $1.8 \mathrm{~S} \mathrm{~m}^{-1}$ at the foot of the mound that climax at $2.8 \mathrm{~S} \mathrm{~m}^{-1}$ in a plateau above the mound summit. Thus, the mound summit is expected to appear more conductive in $1 \mathrm{D}$ inversion models due to the $3 \mathrm{D}$ distortion caused by the mound geometry. In comparison to the other models, Model 2 and Model 4 (Figs 9g and i) exhibit the largest variations of apparent conductivity along the profile. Here, the apparent conductivity immediately increases when the system approaches the conductive mound and reaches a maximum approximately $50 \mathrm{~m}$ from the mound centre. Across the summit apparent conductivity decreases, which will cause a pronounced conductivity decrease in 1D inversion models (see Section 4). Moreover, the curves of Model
2 and Model 4 only differ at $19.3 \mathrm{~ms}$ requiring sufficient data quality at late times $(t>10 \mathrm{~ms})$. Thus, a homogenous SMS mound is difficult to distinguish from a conductive, $30 \mathrm{~m}$ SMS shell for the acquired MARTEMIS data.

If the SMS is confined to the region around the mound summit (Model 3, Figs 9c and h), the response is a mixture of Models 1, 2 and 4 . The apparent conductivity first decreases during the transition along the lower flanks and then increases, as observed in Model 1. Across the summit, a decrease of apparent conductivity is observable at $t<8 \mathrm{~ms}$, which is comparable to Models 2 and 4 . This behaviour is attributed to the $3 \mathrm{D}$ geometry of the conductive summit, but less pronounced due to the decreased volume of the small-scale SMS deposit.

The apparent conductivity pseudo-section and profile curves for Model 5 differ from the remaining models (Figs 9e and j). For early times, the curve is characterized by a sharp peak above the mound summit, which flattens out to a wide plateau at late times. The lateral mound dimensions are accurately mapped using apparent conductivity curves. However, amplitude variations are comparable to Model 1 (Fig. 9a) and could prevent an accurate delineation of the SMS deposit based on the apparent conductivities alone.

Overall, the 3D amplitude analysis indicates that a sufficiently large SMS deposit located on a 3D mound is detectable using either CSEM or TEM. Since the TEM system is designed to detect small-scale conductivity anomalies, it also enables high lateral detectability. In turn, CSEM has a higher penetration depth, and thus, may be more effective in delineating the thickness of SMS deposits using multifrequency inversion. The modelling has demonstrated that both systems require navigation close to the seafloor to maximize the seafloor response in the obtained signal. Furthermore, the analysis confirms that both systems are sensitive to $3 \mathrm{D}$ effects caused by the mound geometry. The impact of these 3D effects on 1D (TEM) and 2D (CSEM) inversion models is analysed in Section 4. 

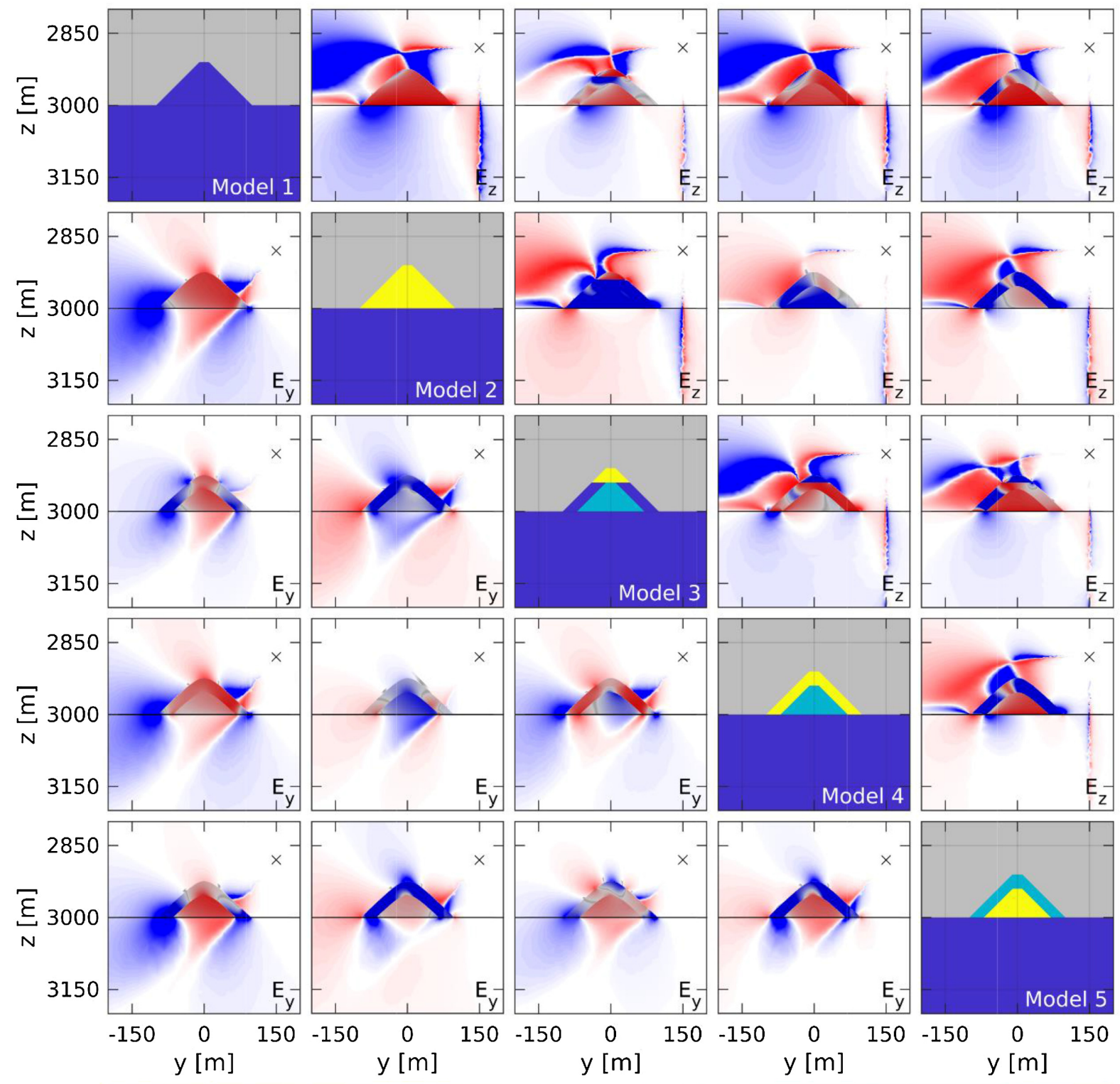

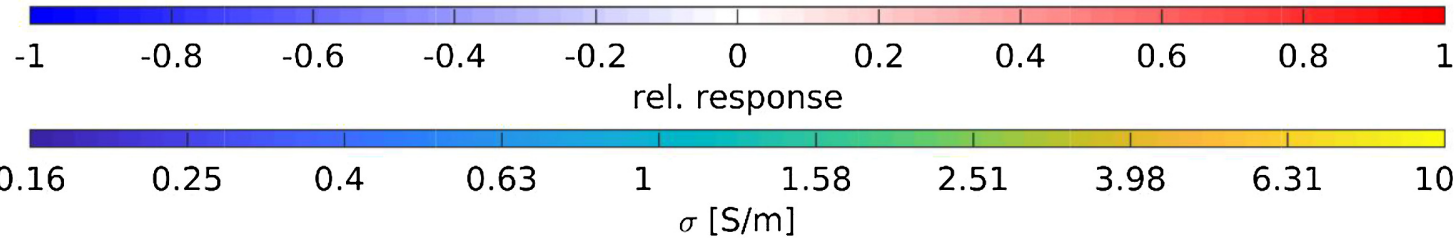

Figure 7. Relative response and 2D cross-sections of the investigated 3D models shown in Fig. 4. The image is organized as a matrix. The main diagonal illustrates the investigated models. The upper triangular section shows the relative response in the $E_{z}$ component of the corresponding models located in the respective row and column. The lower triangular section is analogous, but for the $E_{y}$ component. The relative response is plotted for values between 1 and -1 , which corresponds to a relative difference in signal amplitude of \pm 100 per cent. The transmitter position is marked by a cross in each image.

\section{INVERSION OF SYNTHETIC 3D DATA}

We interpreted the synthetic data using the standard inversion procedures for each method. The 2D CSEM inversion models illustrated in Fig. 10(left) were obtained using MARE2DEM (Key 2016). We follow the synthetic studies of Key (2016) by using a random Gaussian error of 4 per cent on the amplitude and require a minimum normalized amplitude larger than $10^{-15} \mathrm{~V} \mathrm{~m}^{-1}$ for all frequencies. Note that navigation (position/orientation of transmitter and receiver) is precisely dictated in this synthetic study, and as a consequence, data error floors are typically lower than for measured data (especially in $E_{\mathrm{z}}$ ).

TEM conductivity models in Fig. 10 (right column) were derived by inverting the induced voltage transients using an Occam-based inversion scheme (Constable et al. 1987). An average error model was derived from the measured data and imposed on the synthetic 3D TEM data. For TEM data, it is easier to apply a realistic error model that is derived from measured data, as navigational parameters are irrelevant due to the rigid design of the MARTEMIS system. 


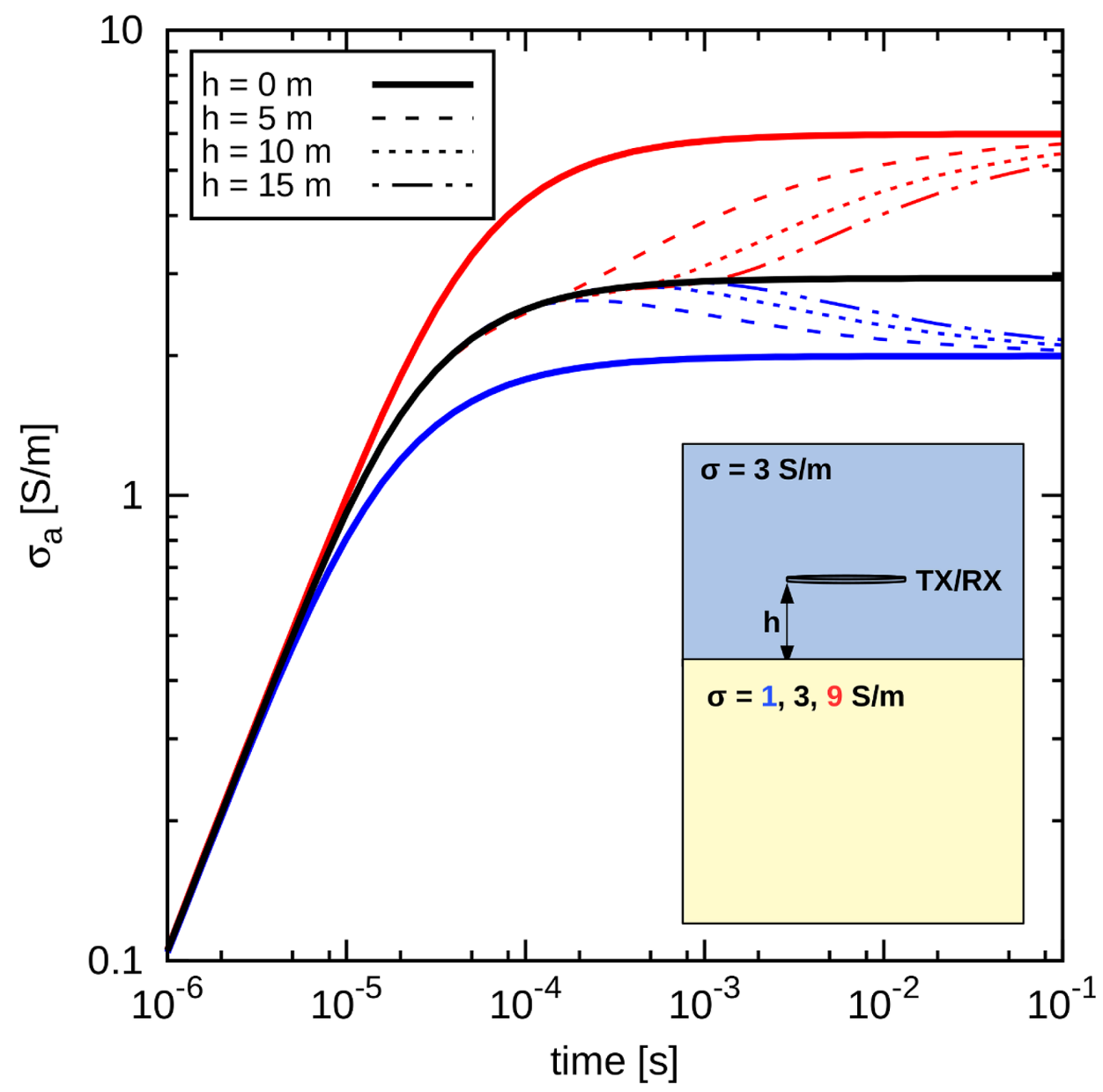

Figure 8. Apparent conductivity curves of a coincident loop TEM system calculated for specific transmitter/receiver elevations in a double half-space environment. The conductivity of the lower half-space is varied between values of 1,3 and $9 \mathrm{~S} \mathrm{~m}^{-1}$ represented by the blue, black and red colours, respectively. Different elevations are illustrated by the different line styles.

A minimum relative error of 1 per cent was used with an absolute error floor of $2 \times 10^{-10} \mathrm{~V} \mathrm{~m}^{-2}$. The typical error of measured TEM data increases with time due to the rapid decay of the induced voltage. Thus, data at times later than where the absolute error floor is reached are neglected in the inversion.

The inversion models were evaluated in terms of data fit using a root-mean-square (rms) and normalized residual misfit (Fig. 11). For both CSEM and TEM data, the rms describes the sum of absolute difference between real and expected data normalized by the corresponding data error (Key 2016). The normalized residual refers to the absolute difference of each datum weighted by its corresponding error. To compare the data fit achieved by the 1D TEM inversion to the one obtained by the 2D CSEM inversion, the mean rms of all 1D TEM inversion models is calculated. Note that this does not incorporate any requirement for neighbouring models to be alike.

The top row of Fig. 10 shows inversion models of CSEM and TEM for a homogeneous mound with the background conductivity of $0.2 \mathrm{~S} \mathrm{~m}^{-1}$ (Model 1). As expected, the seafloor conductivity increases near the mound summit, indicating the sensitivity of both systems to the $3 \mathrm{D}$ geometry of the mound (Figs 10a and c). The comparative 2.5D/3D CSEM forward modelling study illustrated in Fig. S2 in the Supporting Information (top panels) demonstrates that amplitude variations are less pronounced for the $3 \mathrm{D}$ model compared to the corresponding 2D model (Supporting Information
Fig. S2, top row). This reduced amplitude forces the 2D inversion to introduce a conductive structure at the mound summit in order to fit the 3D data adequately. Such feature may be mistakenly interpreted as small-scale SMS near the summit (Fig. 10g) or buried SMS (Fig. 10m) as these inversion models are quite similar. Although the TEM inversion models are qualitatively comparable to the DASI-Vulcan inversion models, the TEM data exhibits an additional characteristic that is apparent in the normalized residuals of Fig. 11(u). A 1D conductivity model is insufficient to fit the 3D data at early and intermediate times as the mound flanks cause the induced voltage to decrease to amplitudes that cannot be reached using a 1D model with fixed seawater conductivity. Hence, the resulting inversion models appear more resistive than in the original 3D model, but fail to achieve an adequate data fit.

The inversion models for a homogeneous SMS mound (Model 2) also exhibit distinct artefacts that are associated with the $3 \mathrm{D}$ geometry of the mound (Figs 10d and f). For CSEM, the conductive mound is relatively well reproduced by the $2 \mathrm{D}$ inversion, with a final rms of 1.11 (Fig. 10d). However, additional resistive structures are introduced beneath and on either side of the mound. This artefact appears because the $3 \mathrm{D}$ response of the conductive mound has a larger amplitude at all frequencies compared to the corresponding 2.5D response (see second row of Fig. S2 in the Supporting Information), forcing a resistive anomaly to be introduced in the $2 \mathrm{D}$ inversion model to account for this difference. This anomaly could be 

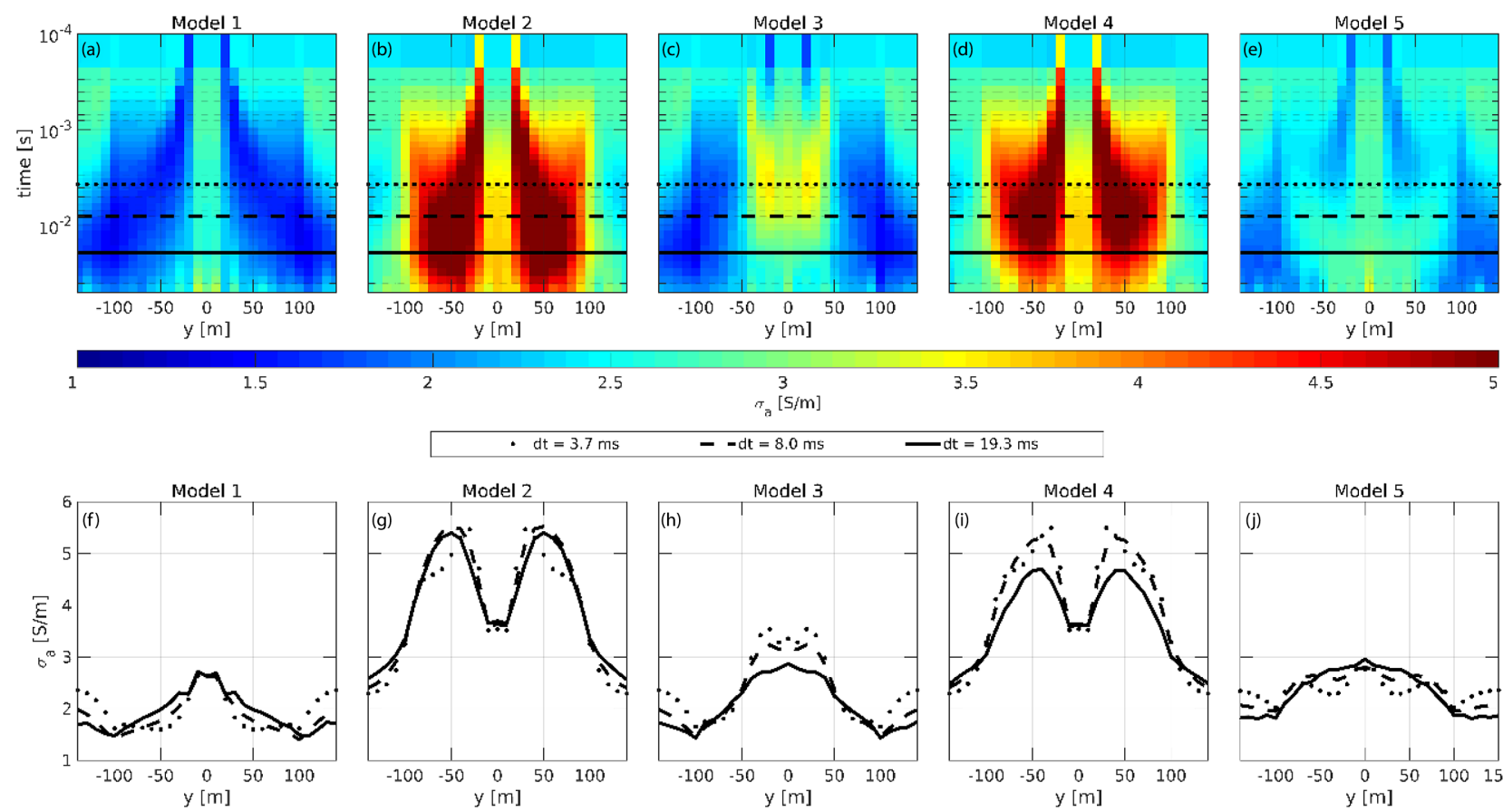

3.5

- $\mathrm{dt}=19.3 \mathrm{~ms}$
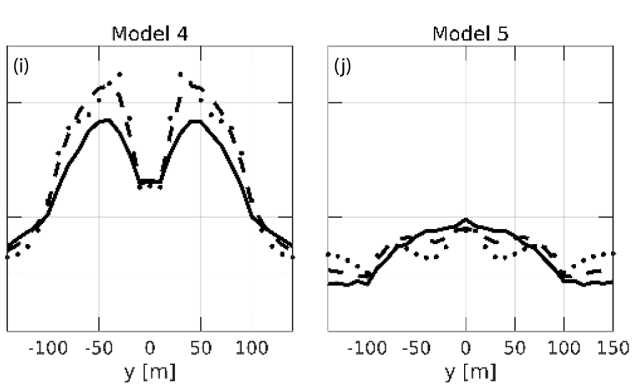

Figure 9. Apparent conductivity pseudo-sections and corresponding profile curves for Model 1 through 5 displayed in Fig. $4 \mathrm{~b}$ through f. The sub-figures show apparent conductivities along the profile for a TEM system located $10 \mathrm{~m}$ above the seafloor. The curves shown in the bottom panel represent values at selected time delays of 3.7, 8.0 and $19.3 \mathrm{~ms}$ in dotted, dashed and solid lines, respectively.

falsely interpreted as a separate geological unit beneath the mound that may lead to false conclusions regarding the stockwork and/or fluid migration paths. The TEM inversion models for Model 2 also contain significant artefacts that are attributed to the 3D geometry of the conductive mound (Fig. 10f). The most prominent feature appears near the mound summit, where the conductivity drops to values ranging between 1 and $4 \mathrm{~S} \mathrm{~m}^{-1}$. This effect is observable in the apparent conductivity curves which also decrease across the mound summit. Hence, quantifying the volume of SMS across the mound is technically challenging without a proper $3 \mathrm{D}$ analysis. In turn, the flanks of the mound appear conductive and remain well defined in terms of lateral extent of the original model.

The inversion result for Model 3 (Fig. 10g) is similar to that for Models 1 and 5 (Figs 10a and m), but shows a slight conductivity increase at the mound summit. This result suggests that DASI-Vulcan CSEM is capable of detecting small-scale SMS accumulations confined to the mound summit. However, it remains questionable whether such small-scale feature would also be apparent when interpreting real data, where data errors are additionally imposed by bias of navigational uncertainties. A vague conductivity increase at the mound summit may therefore be obscured by the increased data uncertainty. In contrast to CSEM, the TEM inversion models accurately reproduce the lateral extent of the conductive cap, which is confined to the lateral limits of the original model (Fig. 10i). However, the observed SMS conductivity is underestimated in the inversion models and the lower boundary of the conductive cap is poorly defined by the 1D inversion models. These limitations are partly explained by the limited time range of the transients (Figs 9g and i), but are also a feature of TEM resolution, which is naturally more sensitive to the upper boundary of conductive layers. Similar to Models 2 and 4, a slight conductivity decrease is distinguishable along the summit, but is less prominent in comparison.

Aside from the shape and geometry of the resistive artefact located beneath the mound in the CSEM model, CSEM and TEM inversion models for Model 4 (Figs 10j, 1) are qualitatively indistinguishable to Model 2 (Figs 10d and f). This similarity suggests that neither method, as implemented in our experiment, can differentiate between a homogeneous mound and one consisting of a $30 \mathrm{~m}$ thick, conductive apron. This result is expected for the MARTEMIS system since it is designed to map only the uppermost tens of metres along the profile. Moreover, the loop source poorly resolves resistive layers, and so the TEM method is mainly effective in detecting the lateral extent of the SMS. In comparison, CSEM has a greater depth penetration capability (geometry dependent) and is more sensitive to resistive bodies due to the galvanic coupling of the current system. However, the differences between the inversion models for the conductive shell (Model 4, Fig. 10j) and the homogeneous mound (Model 2; Fig. 10d) are still small. DASI-Vulcan is more sensitive to the contrast between the SMS and the resistive basaltic background than to the internal conductivity contrast within the mound. Hence, differentiation between a homogeneous and heterogeneous mound would require very high data quality, which could be enhanced by decreasing the towing altitude and using more receivers (see Fig. 7).

Model 5 represents an SMS deposit of $10 \mathrm{~S} \mathrm{~m}^{-1}$ buried beneath a $30 \mathrm{~m}$ overburden of $1 \mathrm{~S} \mathrm{~m}^{-1}$. The resulting inversion models (Figs 10m and o) indicate that TEM can differentiate a buried deposit from a seafloor-based deposit. However, the signature of the deposit is obscured by the superimposed 3D distortion of the mound and may not be identifiable in measured data when using a $1 \mathrm{D}$ inversion approach. Along the flanks of the mound, a conductivity increase with depth is observable, although the inverted values are lower than the true conductivities (Fig. 10o). In comparison, the CSEM inversion model in Fig. 10(m) is practically identical to Model 1 (Fig. 10a). Consequently, we infer that delineation of a buried SMS deposit in a mound is not feasible using CSEM with the given transmitter/receiver configuration and requires more receivers at different offsets and lower towing altitudes. 

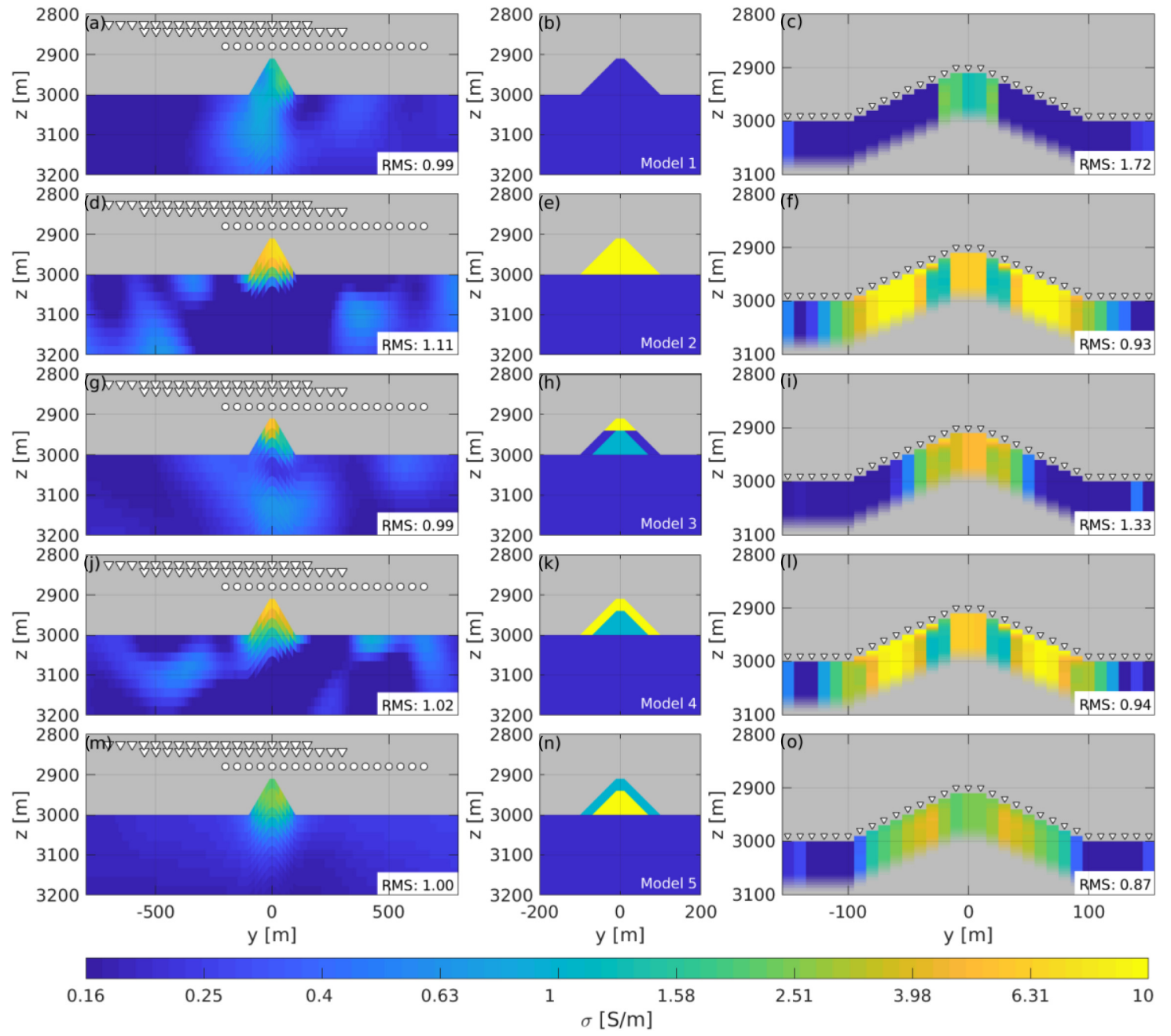

Figure 10. Inversion models for the synthetic 3D data presented in the sections above. (Left column) 2D Inversion models for CSEM sorted from top to bottom by the corresponding 3D model displayed in the centre column. Triangles represent receiver positions, whereas circles illustrate transmitter locations. (Right column) 1D inversion models of synthetic 3D TEM data. Triangular markers represent the position of both transmitter and receiver. Note that the conductivity of the seawater is not shown in these models, but is included in the inversion process as a fixed parameter at $3 \mathrm{~S} \mathrm{~m}^{-1}$. Also, we assume the projected bathymetry underneath the transmitter to be the true 2D bathymetry. Vertical and lateral axis are not consistent between CSEM and TEM. Data misfit of the final inversion models are displayed in for of rms.

\section{INVERSION OF MEASURED DATA}

Along the profiles crossing directly above Shinkai, comparable distortions are apparent in both the synthetic and the measured data. In the following, we present inversion models for a subset of the measured TEM/CSEM data to illustrate this effect. SMSs were visually identified at Shinkai that generate a significant signature in the EM data (Gehrmann et al. 2017; Hölz et al. 2017). In the following, the focus lies on identifying inversion artefacts which are consistent with the synthetic study of Section 4 and attributed to the 3D geometry of Shinkai. No attempt is made to quantify the amount or volume of SMS in this region.

Data processing prior to inversion involved standard schemes for both CSEM and TEM data. For the Vulcan data, the processing procedure was adapted from Myer et al. (2011) and began with transforming every full period into the frequency domain. The frequencies of interest were normalized by the complex source dipole moment, the frequency-dependent amplifier gain and the receiver dipole length. Data were stacked over $60 \mathrm{~s}$ windows and stacking errors were redefined to incorporate navigational uncertainties using 2D forward modelling (see Section A2 of the Supporting Information). Aside from the horizontal and vertical location of both transmitter and receivers, five additional navigational parameters are of relevance when defining the measurement geometry. These are the transmitter azimuth and dip angles (Fig. S3a in Supporting Information), plus three further receiver angles roll $(\alpha)$, pitch $(\beta)$, and heading $(\theta)$ that are explained in Key \& Lockwood (2010) and illustrated in Fig. S3(b) of the Supporting Information. To derive realistic relative error floors for each data point along the profile, we use the projected 2D bathymetry model and assume a homogeneous seafloor conductivity of $1 \mathrm{~S} \mathrm{~m}^{-1}$. Subsequently, the synthetic response was calculated for the measured navigational parameters and compared to the response where each geometrical parameter is perturbed by either $0.5^{\circ}$ or $1 \mathrm{~m}$ (see Figs $\mathrm{S} 4 \mathrm{~b}$ and c in the Supporting Information). The final relative error floor was determined by calculating the sum of relative differences (errors) to the response with the original navigational parameters (Fig. S4d in the Supporting Information). Finally, minimum stacking errors were adjusted where necessary to the redefined error floor. 

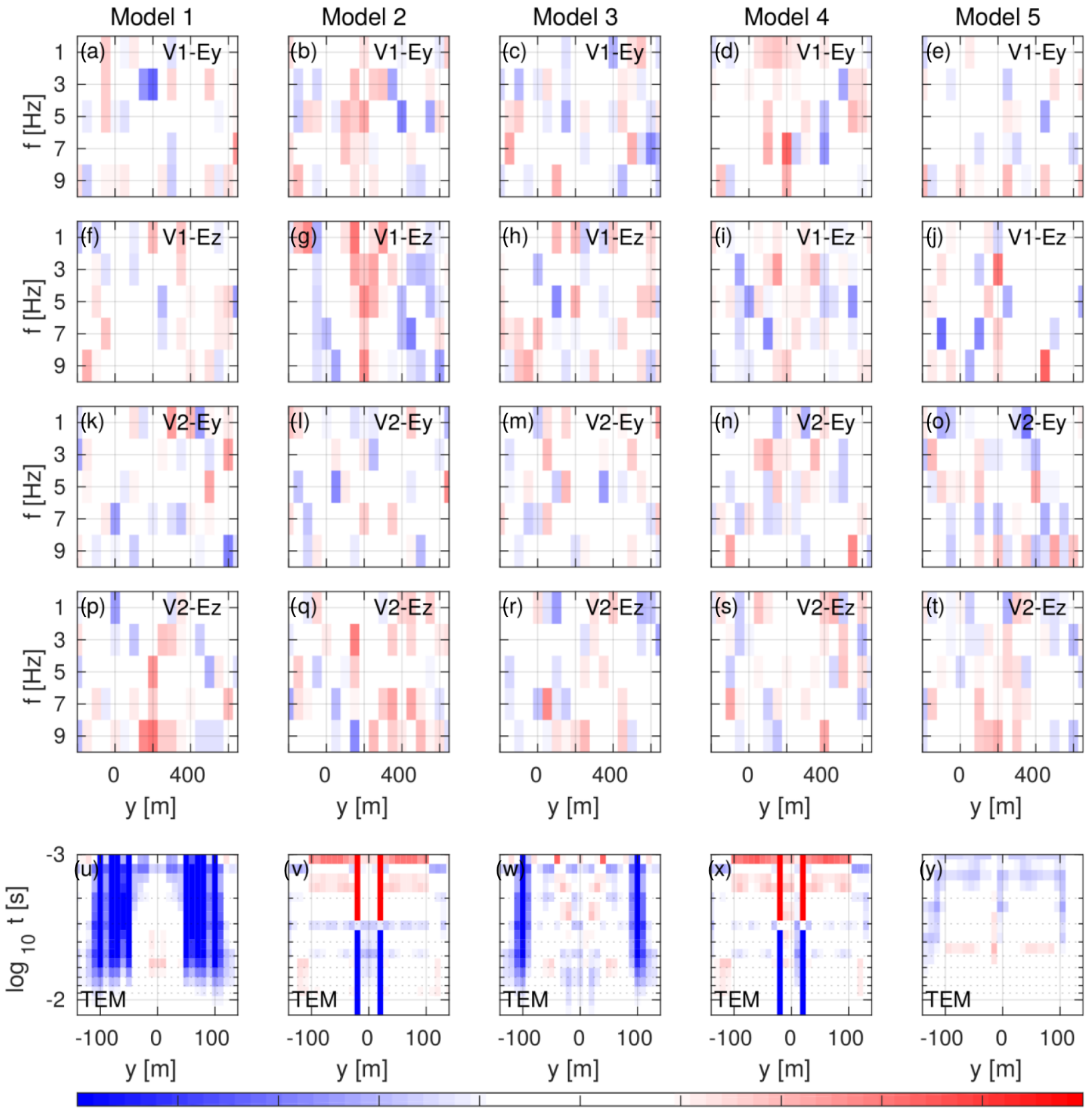

$$
\begin{array}{cccccc}
-5 & -4 & -3 & -2 & -1 & 0 \\
& & & & \text { normed residual }
\end{array}
$$

1

Figure 11. (a-t) Normed residual of the CSEM data misfit at odd frequencies between 1 and $9 \mathrm{~Hz}$ for each of the five models (left to right) displayed in Fig. 4. Normed residuals are displayed for the $E_{y}$ and the $E_{z}$ field component at Vulcan 1 (V1) and Vulcan 2 (V2) receiver. (u-y) Normed residuals of TEM transient misfit between $10^{-3}$ and $2 \times 10^{-2} \mathrm{~s}$. Misfits between -1 and 1 are blanked, as they are fitted within the assumed error bars of the data.

MARTEMIS data were processed using the schemes of e.g. Munkholm \& Auken (1996) and Hölz et al. (2015). The measured time-series were collected over $20 \mathrm{~s}$ intervals, levelled and subsequently log-gated and gate stacked. Stacked transients were calibrated with data acquired within the water column to remove static effects superimposed on the measured data (Hölz et al. 2017). For the 1D TEM inversion, a minimum relative error of 1 per cent was defined and all data acquired before $1 \mathrm{~ms}$ and below the absolute noise floor $\left(2 \times 10^{-10} \mathrm{~V} \mathrm{~m}^{-2}\right)$ were neglected in the inversion.

The DASI-Vulcan system detects conductive anomalies at Shinkai and Southern mounds (Fig. 12a). The model indicates a conductive area beneath each mound which is interpreted as SMS. This conductive region is bounded by a resistive unit with a conductivity below $0.1 \mathrm{~S} \mathrm{~m}^{-1}$. This resistive body could be an artefact, as similar features are reproduced using the synthetic 3D inversion studies of Model 2 and Model 4 (Figs 10d and j), or could represent a separate geological unit beneath the conductive SMS deposit. A second feature that may be related to $3 \mathrm{D}$ distortions lies beneath the small-scale bathymetry anomaly west of Shinkai (Fig. 12a), and appears to be more conductive than the background conductivity, but less conductive than SMS deposits. This type of feature is also reproduced in the synthetic data inversions for Model 1 and Model 


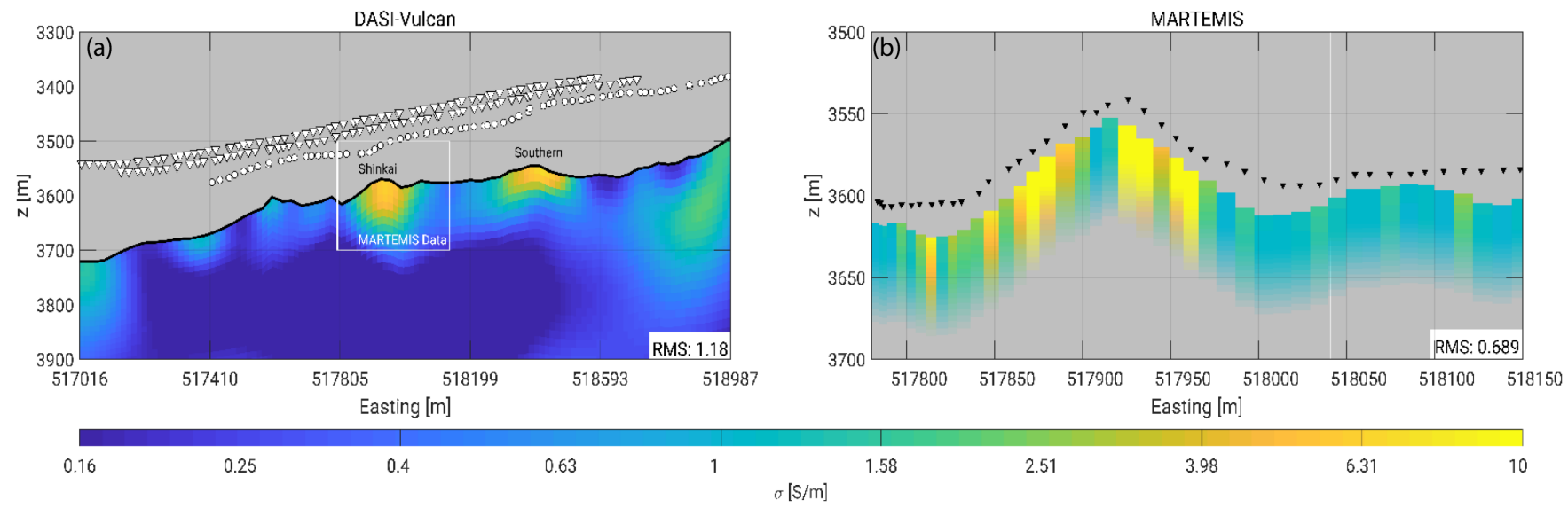

Figure 12. Inversion models of measured EM data for selected profiles highlighted in Fig. 2. (a) 2D inversion model of the DASI-Vulcan data. Transmitter positions are illustrated with circles, receivers, with triangles. The extent of the MARTEMIS profile shown in (b) is highlighted by the white box. (b) Stitched 1D inversion models for data obtained by the MARTEMIS system. Triangular markers represent the position of the coincident-loop antenna. Note, profiles are projected onto their corresponding easting coordinate and are not completely parallel (Fig. 2).

5 (Fig. 10a), where the mound (bathymetry anomaly) appears more conductive compared to the background, and therefore could be introduced by a 3D distortion of the data.

Within Shinkai and Southern mounds, the conductivity distribution appears homogeneous, which coincides with the synthetic inversion of Models 2 and 4 (Figs 10d and j). Consequently, the presence of SMS is detected robustly, but a clear delineation of the vertical deposit dimensions is not feasible without incorporating additional structural constraints to the $2 \mathrm{D}$ inversion.

The MARTEMIS inversion models (Fig. 12b) allow clear delineation of the SMS occurrence. However, the conductive layer is clearly interrupted close to the mound summit, similar to features in our synthetic 3D forward/inverse modelling studies. In turn, the flanks of the mound appear conductive, suggesting a large SMS accumulation (similar conductivity distribution as in Models 1 and 3). Unfortunately, a delineation of SMS thickness is challenging using the acquired MARTEMIS data, as modelling shows that this requires sufficiently high signal-to-noise ratios at late times $(t>10 \mathrm{~ms})$. Unfortunately, the acquired data do not provide this. Yet, the data do indicate that the seafloor outside the mound appears more resistive and rather homogeneous, implying that possible SMS around the mound is either located at greater depth and therefore not visible for TEM data, or confined to areas beneath the mound.

\section{DISCUSSION}

SMS deposits are often associated with mounds that extend several tens to hundreds of meters above the seabed. We have shown that both marine TEM and CSEM data are capable of detecting different types of SMS adequately, but also show that they are susceptible to distortions caused by 3D bathymetry, which may obscure the interpretation using the available 1D (TEM) and 2D (CSEM) inversion schemes.

The presented modelling studies highlight that DASI-Vulcan CSEM is sensitive to seafloor conductivity anomalies when receivers are situated at (relatively) short offsets and altitudes between the source and the mound. The interpretation of synthetic data suggests that 3D mounds cannot be discretized adequately using the presently available $2.5 \mathrm{D}$ modelling approaches, which introduces additional structure in the corresponding $2 \mathrm{D}$ inversion models. Moreover, the effect of 3D bathymetry on navigational parameters of the towed CSEM system (e.g. altitude of transmitter or receiver with respect to the mound) are an additional source of uncertainty in the interpretation. Thus, DASI-Vulcan experiments targeting shallow SMS would benefit from 3D inversion where offprofile bathymetry could be accurately incorporated as a priori information in the inversion routine. In addition to calculating the correct electromagnetic response of the bathymetry, a 3D inversion would ensure that the elevations and horizontal positioning of both transmitter and receiver are correct and are properly accounted for in the interpretation.

The 3D modelling of MARTEMIS data illustrates the sensitivity of horizontal loop systems to small-scale conductivity anomalies situated on, or within the shallow seafloor. The data are effective in delineating the lateral extent of SMS, but may be unsuited to accurately delineate the lower boundary of thick SMS deposits. This is also an issue of sufficient data quality at late times and could be optimized by increasing signal-to-noise ratios (e.g. using larger loops, increased current of longer stacking times), or by minimizing measurement altitudes to increase the seafloor response of the signal. Similar to DASI-Vulcan CSEM, the MARTEMIS data show distinct features related to $3 \mathrm{D}$ distortions caused by the seafloor topography. Although 1D inversion seems sufficient to characterize SMS accumulations along the mound flanks, the derived models do not reflect the true seafloor conductivity distribution at its summit. Hence, a 3D inversion of coincident-loop TEM data could also seem meaningful to accurately delineate the seafloor conductivity structure in this region and help quantify the total amount of available SMS.

\section{CONCLUSIONS}

Our forward and inverse modelling studies show that the CSEM and TEM methods can be used to detect SMS deposits, as illustrated by the date measured near the Mid-Atlantic Ridge. Synthetic 3D forward modelling illustrates that the excited EM field of either source is perturbed to a measurable degree when large occurrences of conductive SMS are present, which underlines the feasibility of both methods. However, small-scale conductivity structures within an SMS mound only result in minor amplitude perturbations for CSEM that may be obscured by the data uncertainties. Future DASI-Vulcan 
CSEM applications for SMS exploration would benefit from additional receivers at both short and long offsets, combined with lower acquisition altitudes (if real-time acoustic navigation is available) to maximize the response of the seafloor in the recorded signal.

Two-dimensional inversions of synthetic 3D CSEM data show that for the given offsets, CSEM can detect SMS. The 2D inversion models clearly highlight the mound as a conductive zone when SMS is present. Ambiguity of the conductivity distribution appears outside the conductive mound, where additional resistive structure is introduced in the model. This effect could pose a problem during the interpretation of 2D inversion models, since it is difficult to differentiate between existing geological features and inversion artefacts beneath the mound that could lead to false conclusions regarding the stockwork and fluid migration paths of the hydrothermal system. Until 3D CSEM and TEM inversion algorithms are widely accessible, careful assessment of the 3D bathymetry is therefore necessary before quantifying the amount and interpreting the origin of an SMS deposit.

MARTEMIS applications seem to be a reliable geophysical tool for exploration of exposed, or partly buried SMS deposits. Our synthetic studies show that the lateral extent of conductive deposits can be reproduced accurately using a $1 \mathrm{D}$ inversion approach or apparent conductivity curves. However, inversion artefacts are present at the mound summit and along a resistive mound flank that we affiliate with $3 \mathrm{D}$ bathymetry. Furthermore, the poor resolution for the lower boundary of a $30 \mathrm{~m}$-thick SMS occurrence prevents a robust delineation of SMS thickness. A clear assessment of the 3D effect using forward modelling also seems useful for TEM applications to improve the interpretation beyond the reliability of the 1D inversion models.

We conclude that inversion artefacts that appear in the synthetic inversion studies of both CSEM and TEM data are also observable in the inversion models of the data acquired. Although the origin of some structures in the inversion models of the measured data are definitely considered ambiguous, similar features are reproducible using 2D inversions of synthetic 3D data. We conclude that disregarding the off-axis (3D) bathymetry around mound structures may lead to a misinterpretation of the shallow sub-seafloor conductivity structure and prevent an accurate quantification of SMS in the survey area.

\section{ACKNOWLEDGEMENTS}

This work was funded by the European Union as a part of Blue Mining project: Grant No. 604500, Breakthrough Solutions for the Sustainable Exploration and Extraction of Deep Sea Mineral Resources (EU-FP7). TAM was supported by a Wolfson Research Merit award. We greatly appreciate the comments of Mauro Pezzoli, an anonymous reviewer and Ute Weckmann, which helped to improve the original version of the manuscript. We kindly thank Prof Bülent Tezkan (University of Cologne) for his advice in preparing this manuscript and permission to use sldmem 3t. We thank Sven Petersen and the AUV ABYSS team (GEOMAR) for allowing us to use the acquired high-resolution bathymetry data and Karen Weitemeyer (OFG, former UoS) for her advice in the experiment preparation and for Fig. 1(a). Jennifer Matthews (SIO) is thanked for the original 2006 illustration of the CSEM system presented in the Leading Edge. Thanks to Kerry Key for making MARE2DEM publicly available for scientific use.

\section{REFER E N CES}

Andersen, C., Theissen-Krah, S., Hannington, M., Rüpke, L. \& Petersen, S., 2017. Faulting and off-axis submarine massive sulfide accumulation at slow spreading mid-ocean ridges: a numerical modeling perspectivce, Geochem. Geophys. Geosyst., 18(6), 2305-2320.

Asakawa, E., Sumi, T., Yamakawa, T. \& Kose, M., 2016. Multi-stage and integrated approach for seafloor massive sulfide (SMS) exploration, in Near Surface Geoscience, EAGE, Barcelona, Spain, doi:10.3997/22144609.201602110.

Attias, E. et al., 2018. High-resolution resistivity imaging of marine gas hydrate structures by combined inversion of CSEM towed and oceanbottom receiver data, Geophys. J. Int., 214(3), 1701-1714.

Cairns, G. W., Evans, R. \& Edwards, R. N., 1996. A time domain electromagnetic survey of the TAG hydrothermal mound, Geophys. Res. Lett., 23(23), 3455-3458.

Cheesman, S.J., Edwards, R.N. \& Chave, A.D., 1987. On the theory of sea-floor conductivity mapping using transient electromagnetic systems, Geophysics, 52(2), 204-217.

Comsol, I., 2017. AC/DC Module User's Guide.Available at: www.comsol .com, last accessed 15 Nov 2018.

Constable, S., 2010. Ten years of marine CSEM for hydrocarbon exploration, Geophysics, 75(5), 75A67-75A81.

Constable, S., Kannberg, P. K. \& Weitemeyer, K., 2016. Vulcan: a deeptowed CSEM receiver, Geochem. Geophys. Geosyst., 17(3), 1042-1064.

Constable, S., Parker, R. L. \& Constable, C., 1987. Occam's inversion: a practical algorithm for generating smooth models from electromagnetic sounding data, Geophysics, 52(3), 289-300.

Doyle, M. \& Allen, R.L., 2003. Subsea-floor replacement in volcanic-hosted massive sulfide deposits, Ore Geol. Rev., 23, 183-222.

Druskin, V. \& Knizhnerman, L., 1994. Spectral approach to solving threedimensional Maxwell's diffusion equations in the time and frequency domains, Radio Sci., 29(4), 937-953.

Everett, M. E, Edwards, R. N., Cheesman, S. J., Utada, H., Ferguson, I. J. \& Kwan, K. C. H., 1988. Interpretation of seafloor electromagnetic data in applied geophysics, in Applied Electromagnetics in Materials, pp. 143-153, ed. Miya, K., Pergamon Press.

Galley, A. G., Hannington, M. D. \& Jonasson, I. R., 2007. Volcanogenic massive sulphide deposits, in Mineral Deposits of Canada: A Synthesis of Major Deposit-Types, District Metallogeny, The Evolution of Geological Provinces, and Exploration Methods, ed. Goodfellow, W.D., Geological Accociation of Canada, doi:10.2113/gsecongeo.102.6.1182.

Gehrmann, R. A. S. et al., 2017. Massive sulphide exploration at the midatlantic ridge $26^{\circ} \mathrm{N}$ : an interdisciplinary geophysical study, AGU Annual Meeting, AGU, New Orleans, GP31A-07.

Hannington, M. D., Tivey, M. K., Larocque, A. C. L., Petersen, S. \& Rona, P. A., 1995. The occurrence of gold in sulphide deposits of the TAG hydrothermal field, mid atlantic ridge, Can. Mineral., 33(6), 1285-1310.

Hannington, M. D., Jamieson, J., Monecke, T., Petersen, S. \& Beaulieu, S., 2011. The abundance of seafloor massive sulfide deposits, Geology, 39(12), 1155-1158.

Haroon, A., Lippert, K., Mogilatov, V. \& Tezkan, B., 2018. First application of the marine differential electric dipole for groundwater investigations: a case study from Bat Yam, Israel, Geophysics, 83(2), B59-B76.

Hölz, S., Jegen, M., Petersen, S. \& Hannington, M., 2015. How to find buried and inactive seafloor massive sulfides using transient electromagneticsa case study from Palinuro Seamount in the Tyrrhenian Sea, Underwater Mining Institute Conference, Tampa Bay, FL.

Hölz, S., Haroon, A., Jegen, M., Pertersen, S., Krätschell, A., Hannington, M., Safipour, R. \& Swidinsky, A., 2017. Exploration of seafloor massive sulfide deposits with the novel EM induction system MARTEMIS. Schmucker-Weidelt Colloquium for Electromagnetic Sounding, Breklum, Germany, p.87.

Key, K., 2016. MARE2DEM: a 2-D inversion code for controlled-source electromagnetic and magnetotelluric data, Geophys. J. Int., 207(1), 571588 .

Key, K. \& Lockwood, A., 2010. Determining the orientation of marine CSEM receivers using orthogonal Procrustes rotation analysis, Geophysics, 75(3), F63-F70. 
Kowalcyk, P., 2008. Geophysical prelude to first exploitation of submarine massive sulphides, First Break, 26(11), 99-106.

Kowalczyk, P., 2011. Geophysical exploration for submarine massive sulfide deposits, Oceans'11 MTS/IEEE Kona,1-5, doi:10.23919/OCEANS.2011.6107069.

Kowalczyk, P., 2013. Mapping Submarine Massive Sulfides using electromagnetics: practical and theoretical considerations, MARELEC. Hamburg.

Li, Y. \& Constable, S., 2007. 2D marine controlled-source electromagnetic modelling: Part 2 - the effect of bathymetry, Geophysics, 72(2), WA63WA71.

Morgan, L. A., 2012. Geophysical characteristics of volcanogenic massive sulfide deposits, in Volcanogenic Sulfide Occurrence Model, pp. 115131,eds ,Pat Shanks W.C., III \& Thurston, R., USGS.

Müller, H., Schwalenberg, K. \& von Dobeneck, T., 2015. Challenges in the deep sea: The Golden Eye electromagnetic induction profiler, 75th Annual Meeting of the DGG, DGG, Hannover, Germany.

Müller, H., Schwalenberg, K., Hilgenfeld, C. \& von Dobeneck, T., 2016. Keynote speech - mapping seafloor massive sulfides at the Central Indian ridge with a novel central loop electromagnetic profiler, Near Surface Geoscience 2016: First Conference on Geophysics for Mineral Exploration and Mining, EAGE, Barcelona, doi:10.3997/22144609.201602118

Munkholm, M. S. \& Auken, E., 1996. Electromagnetic noise contamination on transient electromagnetic soundings in culturally disturbed environments, Environ. Eng. Geophys., 1(2), 119-127.

Myer, D.S., Constable, S. \& Key, K., 2011. Broad-band waveforms and robust processing for marine CSEM surveys, Geophys. J. Int., 184(2), 689-698.

Nakayama, K. \& Saito, A., 2016. The seabed TDEM towed by ROV for the ocean bottom hydrothermal deposits, 22nd European Meeting of Environmental and Engineering Geophysics, EAGE, Barcelona, Spain.

Rona, P. A., 2008. The changing vision of marine minerals, Ore Geol. Rev., 33(3-4), 618-666.

Schwalenberg, K., Haeckel, M., Poort, J. \& Jegen, M., 2010. Evaluation of gas hydrate deposits in an active seep area using marine controlled source electromagnetics: results from Opouawe Bank, Hikurangi Margin, New Zealand, Mar. Geol., 272, 79-88.

Schwarzbach, C., Börner, R. U. \& Spitzer, K., 2011. Threedimensional adaptive higher order finite element simulation for geoelectromagnetics - a marine CSEM example, Geophys. J. Int., 187, 6374.

Sinha, M., Patel, P., Unsworth, M., Owen, T. \& MacCormack, M., 1990. An active source EM sounding system for marine use, Mar. geophys. Res., 12(1-2), 59-68.

Spagnoli, G., , Hannington, M., Bairlein, K., Hördt, A., Jegen, M., Petersen , S. \& Laurila, T., 2016. Electrical properties of seafloor massive sulfides, Geo Mar. Lett., 36, 235-245.

Spagnoli, G., Hördt, A., Jegen, M., Virgil, C., Rolf, C. \& Petersen, S., 2017a. Magnetic susceptibility measurements of seafloor massive sulfide mini-cores samples for deep-sea mining applications, Q. J. Eng. Geol. Hydrogeol., 50, 88-93.

Spagnoli, G., Weymer, B.A., Jegen, M., Spangenberg, E. \& Petersen, S., 2017b. P-wave velocity measurements for preliminary assessments of the mineralization in seafloor massive sulfide mini-cores during drilling operations, Eng. Geol., 226, 316-325.

Swidinsky, A. \& Weiss, C.J., 2017. On coincident loop transient electromagnetic induction logging, Geophysics, 4, E211-E220.
Swidinsky, A., Hölz, S. \& Jegen, M., 2012. On mapping seafloor mineral deposits with central loop transient electromagnetics, Geophysics, 77(3), E171-E184.

Von Herzen, R. P., Kirklin, J. \& Becker, K., 1996. Geoelectrical measurements at the TAG hydrothermal mound, Geophys. Res. Lett., 23(23), 3451-3454.

Ward, S. H. \& Hohmann, G. W., 1988. Electromagnetic theory for geophysical applications, in Electromagnetic Methods in Applied Geophysics, pp. 131-311, ed Nabighian, M., SEG.

Weitemeyer, K. \& Constable, S., 2010. Mapping shallow geology and gas hydrate with marine CSEM surveys, First Break, 28(6), 97-102.

Weitemeyer, K., Constable, S. \& Key, K., 2006. Marine EM techniques for gas-hydrate detection and hazard mitigation, Leading Edge, 25(5), 629-632.

Yogeshwar, P. \& Tezkan, B., 2017. Two-dimensional basement modeling of central loop transient electromagnetic data from the central Azraq basin area, Jordan, J. Appl. Geophys., 136, 198-210.

Yu, L. \& Edwards, R. N., 1996. Imaging axi-symmetric TAG-like structures by transient electric dipole seafloor electromagnetics, Geophys. Res. Lett., 23(23), 3459-3462.

\section{SUPPORTING INFORMATION}

Supplementary data are available at $G J I$ online.

Figure S1. Plan view of a (left) 3D conductivity model compared to a (right) $2 \mathrm{D}$ resistivity model. For $2.5 \mathrm{D}$ forward modelling and $2 \mathrm{D}$ inversion, the conductivity in $x$-direction is assumed constant and does not vary.

Figure S2. Comparison of (markers) 3D and (lines) 2D CSEM data for Vulcan 1 and 2 at offsets of 350 and $505 \mathrm{~m}$ from the dipole centre, respectively. Sub-figures are sorted according to the desired field component (left to right) and corresponding models (top to bottom). The black, blue and red colours in each image denote the frequencies 1, 5 and $9 \mathrm{~Hz}$ respectively. Note that for inversion, 3 and $7 \mathrm{~Hz}$ are also included but not illustrated here.

Figure S3. (a) HED transmitter dipole geometry for a typical CSEM experiment. (b) Vulcan receiver geometry and tilt angles. Images are modified after images from the MARE2DEM website and Key \& Lockwood (2010).

Figure S4. Relative data errors for Vulcan 2 receiver located at an offset of $505 \mathrm{~m}$ from the dipole centre. Each navigational parameter is perturbed by $0.5^{\circ}$ or $1 \mathrm{~m}$. The synthetic response of each perturbation is compared to the original parameter to derive a navigational error. For this study, we use the projected 2D bathymetry along the profile and assume the sub-seafloor to be homogeneous at $1 \mathrm{~S} \mathrm{~m}^{-1}$. (a) Illustration of measurement geometry, (b) navigational errors of $E_{y}$, (c) navigational errors of $E_{z}$ and (d) sum of navigational errors of $E_{y}$ and $E_{z}$ at selected frequencies.

Please note: Oxford University Press is not responsible for the content or functionality of any supporting materials supplied by the authors. Any queries (other than missing material) should be directed to the corresponding author for the article. 